\title{
¿Por qué existe el Estado y no más bien la anarquía? (El anarco-comunitarismo de Michael Taylor)
}

\author{
JUAN ANTONIO RIVERA
}

Para Juan Rivera Sandín, mi padre

Se expone la perspectiva anarco-comunitarista de Michael Taylor, y se la distingue de la anarco-capitalista de autores como Murray Rothbard, David Friedman o, en menor medida, Robert Nozick. El anarco-comunitarismo de Taylor está sólidamente asentado en la teoría de juegos; concretamente, en los análisis dinámicos del Dilema del Prisionero. Sobre la base de estos análisis, a los que el propio autor ha hecho contribuciones sustanciales, se pone de relieve la inviabilidad práctica de una anarquía perfecta, sin controles sociales externos. Pero Taylor muestra que hay, con todo, lugar para un orden social sostenido en controles informales y ampliamente descentralizados, es decir, fundado en vínculos comunitarios, y que ésta ha sido la solución al problema del orden social durante la mayor parte de la historia de la especie. Se discuten luego las circunstancias que presumiblemente dieron lugar a la crisis y obsolescencia de la solución anarco-comunitarista y su sustitución por la respuesta institucional basada en la presencia del Estado. Se concluye el escrito ensalzando los méritos teóricos de Taylor pero poniendo en duda la validez de los presupuestos valorativos que animan sus modestas proposiciones de cambio social.

¿Por qué existe el Estado y no más bien la anarquía? Esta cuestión, planteada more heideggeriano, no se encara directamente hasta la sección 4 del escrito. Antes, en la sección 1, se describen las características de los bienes públicos, y se presenta el orden social como el bien público por antonomasia, para explorar luego con brevedad la solución liberal y la anarco-capitalista a la provisión del orden social. El tramo de lectura más pedregosa se abre en la extensa sección 2; allí se indaga cuáles son los requisitos para la cooperación social espontánea mediante el estudio de modelos bipersonales (estático y dinámico) del Dilema del Prisionero; a los modelos N-personales sẹ alude concisamente en las notas. Los modelos estáticos prestan apoyo a la idea hobbesiana de que el orden social es insostenible sin una autoridad central; lo curioso es que los modelos dinámicos parecen desmentir esta idea. He procurado que cualquier lector medianamente perseverante pueda atravesar sin quebranto esta parte del escrito, pero aquellos que no tengan paciencia para los símbolos 
y las gráficas son invitados encarecidamente a dispensarse de la lectura de las partes expositivas y acudir a los apartados de «Conclusiones intermedias». Con ello se habrán perdido una buena porción de detalles interesantes, pero estoy de acuerdo en que vale más perderse detalles interesantes que perder el buen humor. La sección siguiente ( $₫ \mathrm{El}$ anarquismo comunitarista») expone la tesis de Michael Taylor de que es posible un orden social sin Estado, fundado exclusivamente en lazos comunitarios. En la sección 4 se expone una teoría del surgimiento de Estado consistente con la concepción de Taylor, y la última sección se reserva para un breve examen valorativo de dicha concepción ".

\section{PROBLEMAS EN LA PROVISIÓN DE BIENES PÚBLICOS}

\subsection{La naturaleza de los bienes públicos}

Los bienes o artículos en los que habitualmente pensamos (un kilo de manzanas, una lámpara, un libro o un disco) son bienes privados. Pero no todos los artículos que consumimos en nuestra vida son bienes privados ni tampoco los adquirimos en tiendas o supermercados. Existen, ademâs de los bienes privados, bienes públicos. El orden social es, desde luego, un bien público, pero también lo son las ondas de radio que pululan en la atmósfera, la luz de un faro en la costa, el alumbrado de las calles y las mismas calles, los parques de las ciudades, etc. Son bienes públicos porque:

i) Son indivisibles (o de oferta conjunta o no rivales), es decir, el consumo por parte de una persona del bien en cuestión no disminuye la cantidad del bien potencialmente disponible para el consumo de otras personas. La captación, por parte de alguien, de las ondas de radio a través de un receptor no afecta en nada al uso de las mismas ondas que pueda efectuar otro radio-oyente. Si un noctámbulo se beneficia del alumbrado público, eso no disminuye en nada la cantidad de emisión lumínica disponible para los demás transeúntes.

ii) Son no-exclusivos: si están disponibles para una persona, están disponibles para todas las demás ${ }^{2}$. Si un parque es público, ningún ciudadano

${ }^{1}$ El escrito mejoró después de la lectura crítica que de êl hicieron Antonia Nájar, Francisco Lapuerta y Jorge Minguez. Me es muy grato también reconocer la deuda contraida con el celo profesional y la servicialidad de D. Josep Vicens i Planagumà, bibliotecario de la Universidad Autónoma de Barcelona.

${ }^{2} \mathrm{He}$ seguido las definiciones que proporciona Duncan Snidal en «Bienes públicos, derechos de propicdad y organizaciones políticas», recogido en Colomer, J. M. (comp.), Lecturas de teoria politica positiva, Madrid, Instituto de Estudios Fiscales, 1991, pp. 173-217. Michael Taylor distingue entre «no-rivalidad» e «indivisibilidad», que Snidal toma como términos sinónimos. Para Taylor, un bien es no-rival si el consumo de una unidad del bien por un individuo no reducc (para otros que consumen la misma unidad) la utilidad o satisfacción que extraen de dicho consumo. La diferencia entre una y otra propiedad se aprecia mejor en el caso de bienes no-exclusivos con algún grado de divisibilidad: los llamados bienes públicos congestionables. Una playa, una carretera o un parque son bienes congestionables: su uso por parte de una persona reduce el 
puede vedar a otro su disfrute. Y lo mismo cabe decir de las calles, las playas, el acceso al edificio de un ministerio, etc.

Algunos bienes indivisibles son necesariamente no-exclusivos, como el aire limpio o la luz de un faro. Pero algunos bienes indivisibles pueden ser suministrados de modo exclusivo o no-exclusivo. Por ejemplo, una autopista es un bien que exhibe algún grado de indivisibilidad u oferta conjunta (aunque es congestionable, como todos sabemos), pero es factible limitar el acceso a una autopista y condicionar su uso al pago de un peaje.

Es la propiedad de no-exclusividad la que, cuando se añade a la de indivisibilidad, ocasiona el problema en la provisión de bienes publicos a problema del free-rider. Un free-rider es aquel individuo que consume un bien público (y no puede ser excluido de su consumo), pero que no ha contribuido a su suministro ${ }^{3}$. Como perspicazmente hace notar Taylor, para que un free-rider lo sea es preciso que algunos otros no lo sean, pues de no ser así (de actuar todos como free-rider), no habría bien público del que aprovecharse. Si todos son free-riders, nadie puede serlo ${ }^{4}$. Como, en presencia de bienes colectivos, el oportunismo es una tentación perfectamente racional (ipor qué, después de todo, contribuir a la producción de un bien que, una vez elaborado, va a quedar irremediablemente accesible a todos?, ¿no es mejor dejar que sean los demás los que arrimen el hombro?), lo probable parece ser, en efecto, que el talante oportunista se generalice y que, al generalizarse, acabe con toda posibilidad de ser oportunista, es decir, determine que el bien colcctivo no sea suministrado, y todos queden peor por tratar cada uno de quedar mejor.

total disponible del bien para otros. Pero esto no significa, aduce Taylor, que se reduzca la utilidad para los demás; al contrario, puede ocurrir que una persona más que se incorpora al consumo sea bienvenida y eleve la utilidad de los otros, si estos otros son individuos sociables y prefieren, p. ej., una playa concurrida (si bien no congestionada) a una playa vacia. Es de creer, no obstante, que, alcanzado cierto umbral de concurrencia, los que lleguen nuevos no serán tan bien recibidos y, a partir de ese umbral, el bien público (la playa) se convierte en un bien rival. Este ejemplo pone de relieve que «la rivalidad, a diferencia de la indivisibilidad, es estrictanente hablando una propiedad de los individuos (o de sus funciones de utilidad), no de los bienes mismos» (Taylor, M., The possibility of cooperation, Cambridge, Cambridge U. P., 1987, p. 7). No obstante la interesante puntualización de Taylor, en lo sucesivo emplearé de manera intercambiable «indivisibilidad» y «no-rivalidad».

" "Free-riders es una expresión que ha sido variamente traducida al castellano: pasajero gratuito, desaprensivo, beneficiario franco, consumidor libre de cargas, gorrón, polizón, parásito, oportunista, ventajista, aprovechado, tramposo... son algunas de las versiones entre las que se puede elegir.

${ }^{4}$ Michael Taylor y Hugh Ward [en "Chicken, Whales, and Lumpy Goods: Alternative Models of Public-Good Provision», Political Studies, vol. 30, núrn. 3 (1982), pp.350-370, p. 354] han propuesto que el juego apropiado para estudiar la situación del free-rider con éxito (el oportunista que consigue que los demás no lo sean) no es el Dilema del Prisionero, sino el Gallina. [Hay. traducción del artículo de Taylor y Ward en Colomer (comp.), Lecturas de teoria política positiva, op. cit., pp. 219-260]. Se puede consultar también con provecho el excelente estudio de Fernando Aguiar, «La lógica de la cooperación», Zona Abiera, 54-5 (1990), pp. 7-43; especialmente pp. 23-5. 


\subsection{El orden social como bien público}

Hay dos sentidos en que se puede hablar de orden social:

1) El más restrictivo es el hobbesiano: orden social significa tanto seguridad interna o paz doméstica, cuanto seguridad externa (frente a posibles agresiones foráneas).

2) En otro sentido, decir que existe orden social es tanto como afirmar que la vida colectiva es predecible, esto es, que la mayor parte de la gente acata la mayor parte de las normas sociales vigentes la mayor parte del tiempo, y que esto es de conocimiento común. Por lo demás, da aquî lo mismo que concibamos las normas como regularidades de la conducta, o como prescripciones, o como una combinación de ambas cosas 5 .

En lo que sigue, la expresión «orden social» será empleada en el sentido hobbesiano: como paz interna y externa. Así entendido, el orden social es un bien público, esto es, un bien no-rival y no-exclusivo, lo que hace que su suministro sea potencialmente vulnerable al problema de los free-riders. Taylor distingue dos tipos de solucioncs a este problema: las espontáneas o internas y las externas. Las soluciones internas no involucran ni presuponen cambios en la situación. Esto es tanto como decir que no hay cambios en

i) las posibilidades de decisión abiertas a los individuos;

ii) sus preferencias;

iii) ni tampoco sus creencias.

Las soluciones externas operan, en cambio, alterando al menos una de estas variables ${ }^{6}$. Las soluciones internas son las básicas, principalmente porque son autosuficientes. En cambio, las soluciones externas a un problema de provisión de bienes públicos suelen plantear, ellas mismas, otros problemas de provisión de bienes públicos. Por ejemplo, la solución externa basada en el uso de sanciones suscita la dificultad de que el mantenimiento de sanciones es asimismo un bien público y el free-riding es posible que no se resuelva sino que simplemente se traslade de nivel ?.

Las soluciones externas, a su vez, pueden ser de dos clases. Centralizadas, si la iniciativa para modificar las posibilidades, preferencias o creencias de los individuos está concentrada en las manos de sólo unos pocos miembros del grupo. Descentralizada, si tal iniciativa se halla dispersa entre los integrantes del colectivo. La solución externa y centralizada por antonomasia al problema del orden social (entendido como bien colectivo potencialmente acosado por

\footnotetext{
${ }^{5}$ Véase Taylor, M. Community, Anarchy and Liberty, Cambridge, Cambridge U. P., 1982, pp. 44 y 48. También Elster, J., The cement of society, Cambridge, Cambridge U.P., 1989, pp. 1-2.

"Taylor, M., The possibility of cooperation, op. cit., 21-2.

- Alexis de Tocqueville hace algunas observaciones, interesantes como suyas, en torno a este problema en La democracia en América, Madrid, Alianza Editorial, 1980, tomo 1, pp. 75 y 395.
} 
el free-riding) es el Estado. Una presunta solución externa semidescentralizada la proporcionaria el mercado. Y, por último, la comunidad hace las veces de solución externa descentralizada.

En los próximos dos apartados me ocuparé del Estado y del mercado. La sección 2 del artículo estará íntegramente consagrada a las soluciones internas al problema del mantenimiento del orden social. Y la sección 3 indagará los méritos de la respuesta fundada en la comunidad.

\subsection{Estado y orden social: el argumento liberal}

Mancur Olson ha sostenido que «cuanto mayor es el grupo, más lejos estará de suministrar una cantidad óptima de un bien colectivo» ${ }^{8}$. La razón principal que da es que, a medida que crece el grupo, menor es el beneficio marginal para cada individuo del incremento adicional del bien público como resultado de su contribución, de modo que en grupos relativamente grandes el beneficio marginal para el participante potencial es superado por el coste derivado de su aportación, y ésta no tiene lugar. En grupos pequeños es menos probable que esto suceda.

Este «efecto de tamaño» ha sido empleado por los pensadores liberales para argumentar en favor del Estado. En grupos grandes, la autoprovísión de orden por parte de la sociedad civil ha de ser virtualmente descartada. El orden social parece ser algo universalmente deseado por todo grupo humano, pero a medida que éste aumenta de tamaño se aleja la posibilidad de que pueda surtirse a sí mismo de este bien colectivo básico, aquel sin el cual es prácticamente inviable que se produzcan los demás bienes, sean públicos o privados. Se recordará que Hobbes aducía que el desorden meramente potencial origina una omnipresente incertidumbre que erosiona todo incentivo para invertir recursos en proyectos con ganancias aplazadas en el tiempo. Este estado de colapso social generalizado (o estado de naturaleza) es menos preferido por cada uno que una situación de paz sostenida en restricciones mutuas sobre la libertad natural de cada uno. No obstante, será esta situación menos que óptima del estado de naturaleza la que prevalecerá ya que, una vez dada, nadie tendrá interés en autolimitarse unilateralmente a la vista de que los demás no lo hacen. En grupos grandes, además, los procesos de socialización, reforzados por mitos colectivos, rituales religiosos y otros aglutinantes sociales, son impotentes por sí solos para garantizar el orden social. Y la situación no varía sustancialmente si añadimos las sanciones informales, tales como amenazas, murmuración, retirada de la cooperación colectiva, etc., que son bienes colectivos que plantean similares problemas de mantenimiento.

${ }^{3}$ Olson, M., The Logic of Collective Action, Cambridge (Mass.), Harvard U. P., 1965, p. 35. 
En estas condiciones - cuando los individuos desean la paz pero, guiados por su interés personal, son incapaces de producirla como resultado agregado de sus decisiones individuales - es racional para cada uno insitituir un poder político capaz de limitar en igual medida la libertad de todos, de manera que las oportunidades de comportamiento incivil y desaprensivo (aquellas que a la larga perjudican a los mismos que las siguen) se vuelvan más costosas y no sean por más tiempo elegidas. La función básica del Estado sería «atar al mástil» a cada individuo, apretándole los nudos con firmeza, para evitarle las opciones de conducta a la vez tentadoras y autodestructivas.

Hasta aquí el conocido argumento liberal-conservador, de raíz hobbesiana, que resalta elocuentemente tanto la deseabilidad del orden social cuanto que el Estado es el único instrumento para asegurarlo, en especial en sociedades extensas. Pero la presencia del Estado ha sido defendida más recientemente desde líneas de argumentación propias de la izquierda política. El énfasis se desplaza ahora desde la función protectora del Estado a la función redistribuidora. La redistribución solidaria en favor de los desheredados por el azar (natural, social o eventual) es también algo que la mayor parte de los ciudadanos (no digamos que todos) considera moralmente deseable, pero se trata igualmente de un resultado que se ven inhábiles para generar de manera descentralizada, con lo que su producción es confiada a un Estado benefactor. Más recientemente aún, las demandas de intervención al Estado para que dé vida a lo que la sociedad civil, con reconocida impotencia, desea mayoritariamente pero es incapaz de obtener por sí sola, han aumentado en otra dirección: se pide ahora al Estado que ejerza funciones de protección del medio ambiente, que sancione los vertidos contaminantes al aire o a las aguas, que limite la caza de especies en vias de extinción, que controle el crecimiento de la población, etc. Comoquiera que muchos de estos problemas son de rango transnacional, algunos demandan un Estado mundial, que sería el único capaz de producir y suministrar una tal cesta de bienes públicos en rápido crecimiento.

\subsection{Anarco-capitalismo}

Los «libertarios» o «anarco-capitalistas» creen que todos los componentes del orden social pueden ser satisfactoriamente suministrados por el mercado. Su idea directriz es que los problemas con la provisión de bienes públicos son debidos precisamente al carácter público de estos bienes, lo que hace que la conducta del free-rider origine lo que técnicamente se conoce como «externalidades». Una externalidad se presenta siempre que el bienestar de un individuo se ve afectado por la actividad de algún otro individuo. Un fumador causa externalidades negativas a los que están en su entorno, al deteriorar la calidad del aire (que es un bien colectivo). Las externalidades pueden ser también positivas: un ciudadano que cuida con esmero su propio jardín y lo 
mantiene esplendoroso está proporcionando solaz visual a sus vecinos (o simplemente a quien pasee por las inmediaciones). En sentido más estricto, se dice que ha tenido lugar una externalidad si la incidencia de la actividad de una persona sobre el bienestar de otras no puede ser objeto de intercambio, es decir, si el individuo afectado por una externalidad negativa no es compensado por ella en debida forma, o bien no paga por ella, si lo que ocurre es que está disfrutando de una externalidad positiva. Si el furnador abonara los daños que ocasiona a los circunstantes con su proceder, o si los transcúntes y vecinos reconocieran «monetariamente» la deuda de gratitud que tienen con el apacible ciudadano que mima su jardín, desaparecerían las externalidades de un signo $y$ de otro. $O$, dicho con otro giro, las externalidades previas serian completamente internalizadas en el intercambio subsiguiente.

Pero para que las externalidades sean reemplazadas por intercambios explicitos, es precisa una redefinición de los derechos de propiedad y un reconocimiento de los mismos por las partes implicadas. Si, en lugar de considerar el aire de una sala como un bien público, estuvieran bien definidos para cada ocupante de la sala sus derechos de propiedad privada (exclusiva) sobre una porción del aire limpio contenido en ella, entonces el fumador que "poluciona» habría de compensar a los propietarios de las uparcelas de aire» de cuyos recursos se está apropiando indebidamente. La demarcación de derechos de propiedad privados sobre bienes que en la actualidad se consideran de titularidad pública eliminaría de raíz las externalidades y, con ello, los incentivos para actuar como free-rider.

En casos como éste, las características técnicas del bien en juego (el aire limpio) hacen que la delimitación de derechos de propiedad exclusivos sea, más que otra cosa, una solución conceptual, de imposible implementación (al menos de momento). Pero es que, además, un bien colectivo como el orden social parece resistirse por principio a cualquier intento de división o troceamiento en lotes individuales, directamente apropiables. Algunos de los relatos ejemplificadores de los anarco-capitalistas (que tienen ese candoroso aire de comic futurista que les es tan peculiar) parecen no prestar suficiente atención a esta dificultad. Tomemos el caso de los problemas locales de orden social. Los anarco-capitalistas proponen, como parte de la solución, que las calles tuvieran propietarios, en vez de ser de titularidad pública. Con objeto de mantener la seguridad en las mismas, los propietarios acudirían a empresas privadas 0 «agencias de protección». Los libertarios están persuadidos de que, en ausencia de Estado, emergería espontáneamente un mercado de servicios de protección, que sería tan competitivo y eficiente como pudieran serlo otros. Las firmas proveedoras en este mercado ofrecerían distintos tipos y cantidades de seguridad, en respuesta a los gustos de los clientes, en lugar de la seguridad monocromática suministrada por el Estado monopolista. Si ocurriera que dos agencias de protección entraran en conflicto por la defensa de las reclamaciones de sus respectivos clientes, no tendrían por qué dỉrimir sus difcrencias a tiros: 
habria un mercado complementario de empresas especializadas en problemas de arbitraje, e incluso ('ipor qué no?) un tercer mercado de sistemas alternativos de leyes, etc ${ }^{9}$.

El problema con los análisis anarco-capitalistas es que, como ya se indicó, sobrevaloran las posibilidades de fragmentar un bien público, como el orden social, y venderlo en porciones individualmente apropiables en el mercado. Ignoran o minimizan, por decirlo de otra forma, las externalidades que ocasiona la compra privada de servicios de protección. Si yo alquilo los servicios de una agencia de protección, mi vecino también se beneficia de esto (aunque no sea cliente de la agencia) y actúa de facto como un free-rider. Este inconveniente sólo se evita si la agencia de protección es pública (un Estado) o si todas las agencias privadas hacen públicas las listas de sus clientes y encaminan, de este modo, a los malhechores hacia las personas no protegidas por ninguna agencia. Las externalidades positivas para otros de que yo compre servicios de protección privados para mí me disuadirán de contribuir para que otros se beneficien, y la cantidad suministrada de protección será menos que óplima. Estas externalidades positivas iluminan el hecho de que la seguridad es un bien muy imperfectamente exclusivo.

Menos libertarios son los defensores (como Nozick) de un Estado mínimo o Estado protector (en la terminología de James Buchanan), encargado de ofrecer - en régimen de monopolio - seguridad externa e interna. Nozick considera (y su narración es altamente plausible) que la competencia entre agencias de protección conduciría eventualmente a la aparición de una agencia de protección dominante, un proto-Estado ${ }^{10}$. Pero la posición de Nozick tiene sus propios problemas. ¿Por qué se obstina, por ejemplo, en seguir compartiendo con los libertarios la defensa del carácter «inviolable» o absoluto de los derechos de propiedad? Es verdad que esto le facilita el ataque a cualquier concepción redistribuidora de la justicia (como la de Rawls), que necesariamente entrañará una lesión de derechos de propiedad legítimamente adquiridos. No obstante, parece no advertir Nozick suficientemente que la presencia de un Estado, por mínimas que sean sus dimensiones y por mucho que se reduzcan sus tareas a la mera protección de los ciudadanos, supone la financiación pública mediante impuestos, impuestos que colisionarían con la intangibilidad de los derechos de propiedad. La defensa consistente de estos últimos sólo parece ser posible desde posiciones resueltamente anarco-capitalistas ${ }^{11}$.

La opinión de Taylor es que en las sociedades capitalistas el orden social es mantenido por una combinación de Estado, comunidad y mercado. El orden social se puede mantener (y ésta es su propuesta principal) sin Estado y sin

${ }^{4}$ Taylor, M., Community, Anarchy and Liberty, pp. 60-2.

10 Vëase su clásico Anarchy, State, und Utopia, Nueva York, Basic Books, 1974, en especial caps. 3 y 5. pp. 118-9.

"Esta objeción se encuentra en Gray, J., Liberalismo, Madrid, Alianza Editorial, 1994, 
mercado, sólo por medio de la comunidad; también puede ser sostenido el orden social principal (aun si no exclusivamente) por el Estado; pero lo que lc parece inviable es que el orden social sea suministrado exclusiva o principalmente por el mercado. El anarquismo comunitarista de Taylor deberá, según esto, ser cuidadosamente deslindado del anarco-capitalismo expuesto en las líneas precedentes, por más que ambos enfoques coincidan en su rechazo del Estado como instrumento principal para sostener el orden social.

\section{MICRO-FUNDAMENTOS PARA LA ANARQUÍA}

Los problemas en la provisión de bienes públicos (orden social incluido) se suelen tratar como casos del Dilema del Prisionero (DP en adelante) ${ }^{12}$, y se han estudiado con modelos basados en este juego, dotándolos de rasgos cada vez más cercanos a las situaciones de interacción efectiva. El crudo modelo básico del DP (bipersonal y monoperiódico) fue sustituido por modelos $\mathrm{N}$-personales, en que el número de participantes podía exceder de dos. La ampliación

\section{DIMENSIÓN TEMPORAL}

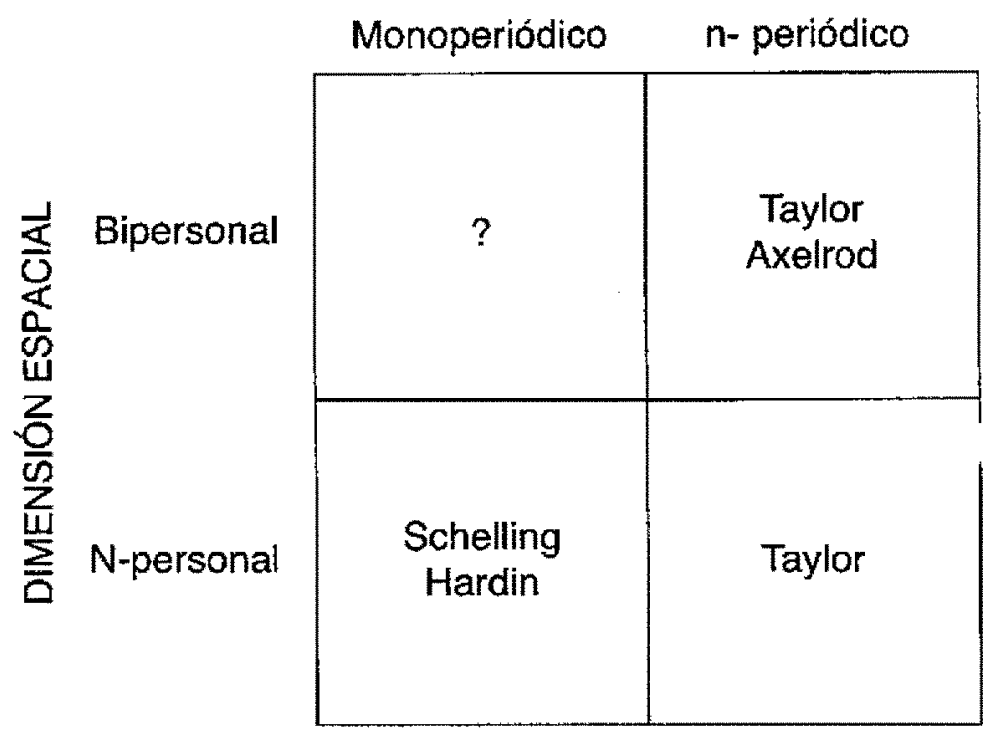

Fig. 1, Las dimensiones «espacial» y «temporal* del DP.

${ }^{12}$ Russell Hardin ha sostenido que xel problema de la acción colectiva y el del dilema del prisionero son esencialmente el mismo» (Collective action, Baltimore, The Johns Hopkins U. P., 1982, p. 25). También, del mismo autor, «Collective Action as an Agreeable n-Prisoners' Dilemma», recogido en Barry, B., y Hardin, R., Rational man and irrational society?, Beverly Hills, Sage, 1982, pp. 121-137. 
de la «dimensión espacial» del modelo no cabe duda que aumentó su realismo, pero quizá el paso decisivo tuvo lugar cuando se incorporó la «dimensión temporals a los modelos, es decir, cuando se tomó en cuenta la posibilidad de repetición n-periódica del DP. En la siguiente matriz se recogen los nombres de los principales impulsores de los diversos modelos del DP para el análisis de problemas de acción colectiva.

Por razones de espacio, y también por ser de más sencilla exposición, me centraré en los modelos bipersonales - tanto estáticos (monoperiódicos) como dinámicos (n-periódicos) -, aunque consagraré un par de notas a contar lo imprescindible acerca de los modelos $\mathrm{N}$-personales. El propósito de esta sección es estudiar las condiciones que han de verificarse para la provisión voluntaria y descentralizada de bienes públicos y, señaladamente, del orden social. En términos más enfáticos, lo que se hace es analizar los microfundamentos para la anarquia perfecta, que definiré como aquella situación en que el orden social se obtiene a través de una solución intema al problema del free-riding, solución en que está ausente el uso de cualquier medio coercitivo para obtener la participación de los individuos en el mantenimiento del orden social.

\subsection{El modelo estático bipersonal}

\subsubsection{Exposición}

Aunque no muy útil para extraer conclusiones fiables sobre el asunto que nos ocupa, el modelo básico DP (estático y bipersonal) nos ayudará a familiarizarnos con el juego e incluso servirá para iluminar algunas de las dificultades que se suscitan cuando se trata de alcanzar la paz social sin recurrir a ninguna autoridad central.

El DP fue inventado hacia 1950 por Merril Flood y Melvin Dresher, investigadores de la RAND Corporation, siendo formalizado poco después por el profesor de Princeton Albert W. Tucker ${ }^{13}$. El relato con el que se suele acompañar el juego puede tomar el siguiente aspecto: dos sospechosos de ser cómplices en un crimen - y a los que, por comodidad, llamaremos Fila y Columnason detenidos por la policía y encerrados en celdas separadas. Cada sospechoso puede optar por hablar inculpando a su compañero, o por permanecer en silencio. Las posibilidades son éstas:

1) Si un sospechoso habla y su cómplice no, el primero sirve de testigo de cargo del otro, al que le caerían cinco años de cárcel, mientras él quedaría en libertad.

2) Si ambos hablan, los dos irían a prisión por tres años.

${ }^{13}$ Más pormenores históricos y anécdotas se pueden encontrar en Poundstone, W., El dilema del prisionero, Madrid, Alianza Editorial, 1995. 
3) Si ambos permanecen callados, sólo se les puede acusar de un delito menor (tenencia ilícita de armas), que les mantendría a la sombra durante un año ${ }^{14}$.

El resumen de las distintas posibilidades se encuentra cn la Fig 2.

Las cuatro casillas representan los cuatro resultados posibles que pueden alcanzarse. Se advertirá que cada resultado depende de lo que decidan ambos prisioneros, no de lo que elija uno solo de ellos. En cada casilla, la cifra que

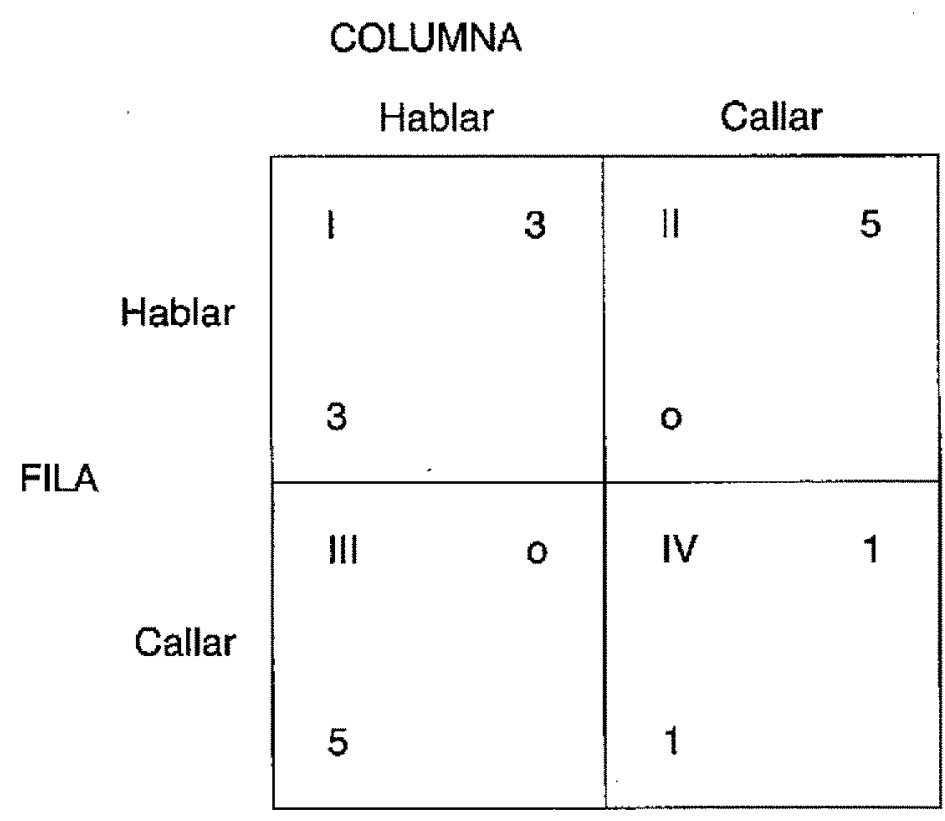

Fig. 2. El modelo básico DP.

está en la esquina inferior izquierda representa el «pago» (años de cárcel) correspondiente a Fila; y la cifra que está en la esquina superior derecha, el pago de Columna.

Para la más perfecta intelección del juego, habrá de tenerse en cuenta que suponemos que los prisioneros Fila y Columna están interesados en reducir al mínimo su posible estancia en la cárcel, y que no son sensibles a sanciones morales, tales como la culpa, pérdida de autoestima, etc., derivadas de escoger «egoístamente». Suponemos también que son inmunes a la empatía, y que la suerte de su cómplice no afecta en nada a su propio bienestar. Por otro

"He tomado el relato de Davis, M., Introducción a la teoria de juegos, Madrid, Alianza Editorial, 1986, p. 122. Me he permitido alterar las cifras para hacerlas coincidir con las que emplea Robert Axelrod en The evolution of cooperation, Nueva York, Basic Books, 1984. 
lado, al estar incomunicados entre sí, queda excluido que un preso pueda amenazar o sobornar al otro, o tratar de alterar de cualquier otra forma su decisión.

Conocidas estas condiciones, ¿qué situación se producirá como resultado de la decisión que toman ambos prisioneros? ¿Qué elegirá cada uno de ellos? El razonamiento de Fila podría ser éste, desmembrado en todos sus pasos:

1) Mi compañero Columna tiene dos opciones: Hablar o Callarse.

2) Supongamos primero que Columna habla. ¿Qué es lo mejor para mí en tales circunstancias?

2.1) Si yo opto por hablar también, estamos en la casilla I, y me corresponden tres años de cárcel.

2.2) Si, por el contrario, me callo, pasamos a la casilla III, y tendría que sufrir cinco años de cárcel.

2.3) Luego me interesa más hablar, al menos en la hipótesis de que Columa hable.

3) Pero supongamos ahora que Columna es tan buen chico que decide callar. ¿Qué me conviene a mí hacer entonces?

3.1) Si yo decido hablar (casilla II), salgo libre.

3.2) $\mathrm{Si}$, en cambio, me inclino a guardar silencio también (casilla IV), me caerá un año.

3.3) Por tanto me interesa más hablar también en la hipótesis de que Columna se calle.

4) La conclusión a la que llego es que me interesa más hablar, haga lo que haga Columna.

Todo el razonamiento anterior se puede resumir diciendo que Fila ha descubierto que tiene una estrategia dominante, y que esa estrategia es Hablar. Un jugador posee una estrategia dominante si tiene a su alcance una forma de actuar que le proporciona al menos tan buenos resultado como las demás $\mathrm{y}$, como mínimo en un caso, resultados mejores. Diremos, además, que Fila tiene en este caso una estrategia fuertemente dominante, pues Hablar le reporta siempre mejores resultados que la estrategia alternativa de Callarse.

Un razonamiento simétrico al expuesto llevaría al jugador Columna a descubrir que, también para él, la estrategia (fuertemente) dominante es Hablar. En la siguiente Fig. 3 senalo con círculos las respuestas optimas de Fila a las posibles opciones de Columna, y con cuadrados las respuestas óptimas de Columna a las posibles opciones de Fila ${ }^{15}$.

Que Fila tiene la estrategia dominante de Hablar se aprecia en que en su fila Hablar (formada por las casillas I y II), los pagos que le corresponden

${ }^{15}$ Tomo en prêstamo esta práctica de Binmore, K., Teoria de juegos, Madrid, McGraw-Hill, 1994, p. 276. 
COLUMNA

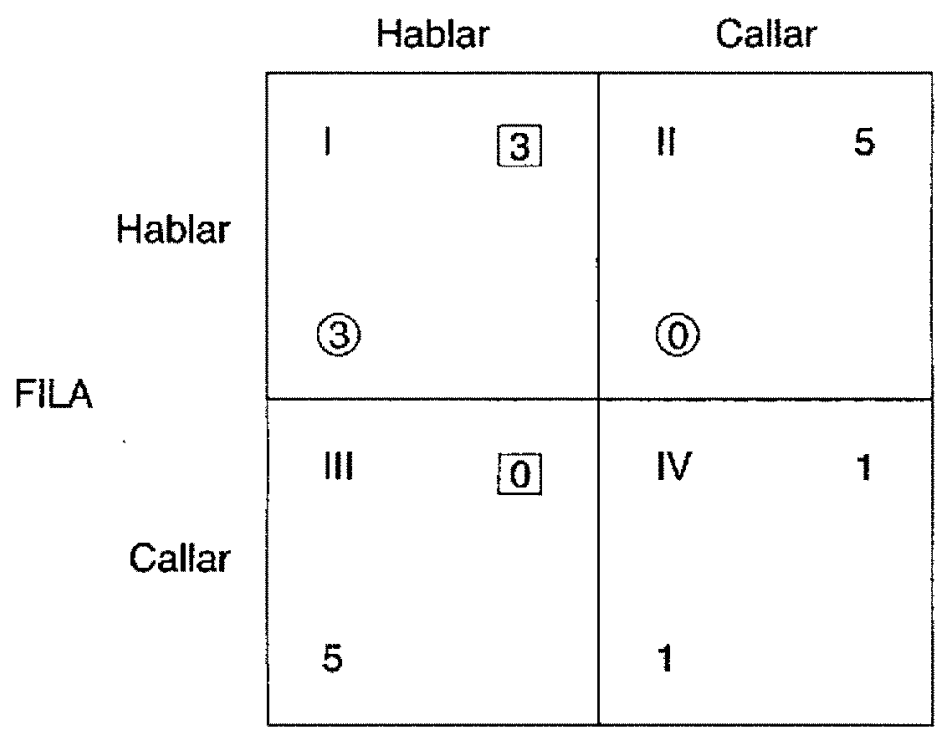

Fig. 3. Estrategia dominante y equilibrio de Nash.

están ambos marcados con círculos. De modo similar, se ccha de ver que Columna tiene la misma estrategia dominante en que en su columna Hablar (formada por las casillas I y III), sus pagos - los de la esquina superior derecha- están marcados con cuadrados.

Diremos también que la casilla I representa el equilibrio de Nash del juego (sólo hay uno en este juego) porque es la única casilla en que los pagos de ambos jugadores están marcados (con círculo y cuadrado respectivamente). Según esto, una situación es un equilibrio de Nash ${ }^{16}$ cuando es el resultado de la elccción, por cada jugador, de su respuesta óptima a la respuesta óptima del otro. También se puede definir un cquilibrio de Nash como aquella situación que, una vez producida, deja sin incentivos a cualquier jugador para modificar unilateralmente su clección de estrategia. En efecto, si, partiendo de la casilla I, imagináramos que Fila modifica su decisión y escoge Callarse, eso empeoraría sus pagos (pasaría de tres años de cárcel a cinco). Y lo mismo ocurriría si fuese Columna el que alterara su decisión ${ }^{17}$.

1 . Así llamado en honor de John Nash, quien fue el primero en formular la noción de equilibrio, hoy de uso común en teoría de juegos, en sus dos históricos artículos «Equilibrium Points in n-Person Games», Proceedings of the National Academy of Sciences of the USA, 36 (1950), pp. 48-9, $y$ «Non-cooperative Games», Annals of Mathematics, 54 (1951), pp. 286-295.

17 Cognoscentes podrían alegar que (Hablar, Hablar) es el equilibrio de Nash del DP básico con estrategias puras, pero que aún queda por indagar si hay equilibrios de Nash cuando se permite a los jugadores emplear estrategias mixias. Hablar y Callar son las estrategias puras del 
Dado que hemos supuesto a los prisioneros preocupados por reducir al mínimo sus años de cárcel, y por ninguna otra cosa, cada uno escogerá su estrategia dominante, lo que convertirá a la casilla I en la solución estable del juego. Estable porque, como se acaba de indicar, el desistimiento unilateral de la estrategia dominante conduce a quien lo lleva a efecto a empeorar sus resultados.

Lo llamativo de esta solución del juego es que es subóptima en el sentido de Pareto. Para entender csta expresión, dcfinamos antes lo que cs una situación Pareto-superior. Una situación B es Pareto-superior a otra A si al pasar de $\mathrm{A}$ a $\mathrm{B}$ hay al menos un individuo que mejora y, además, nadie empeora. Pues bien, una situación es subóptima en el sentido de Pareto (o ineficiente, como también se denomina) si hay por lo menos otra situación al alcance de los participantes en el juego que es Pareto-superior con respecto a ella. Y, en efecto, sucede que la situación descrita en la casilla IV es Pareto-superior a la situación de la casilla I: tanto Fila como Columna mejorarían su suerte si se decidieran a guardar silencio; no obstante lo cual, el óptimo paretiano de la casilla IV se les torna inaccesible si cada uno escoge racionalmente la estrategia que individualmente más le conviene. La elección, por cada uno, de su cstrategia dominante les deja a ambos atrapados en un equilibrio ineficiente (la casilla I), del que ninguno querrá salir unilateralmente.

Esto último deja en claro la necesidad de pactar para escapar de una solución tan manifiestamente mcjorable. Si a ninguno de los prisioneros le interesa modificar su estrategia por separado, en cambio resultaría muy conveniente para los dos llegar a un acuerdo que les comprometiera a guardar silencio. En las condiciones en que hemos imaginado el juego - con los presos incomunicados- esto no es factible. Pero cambiemos ahora radicalmente de escenario: dejemos a los meditabundos prisioneros del relato e imaginemos ahora a dos simples seres humanos que pueden comunicarse libremente, y que están decidiendo si vale la pena entrar en sociedad o no. Las opciones a las que se enfrentan no son ya Hablar y Callar, sino más bien «Respetar las normas de convivencia» o «Incumplirlas».

Los pagos que figuran en la casillas ya no representan años de cárcel sino la valoración ordinal que de los diferentes resultados hacen ambos jugadores, cs decir, el nivel de satisfacción que les proporcionaría cada una de las situaciones posibles a las que les conduciría la combinación de sus decisiones. Por sim-

DP básico. Un jugador usa una estrategia mixta cuando elige con una probabilidad $p(0<p<1)$ una cstrategia pura. Por ejemplo, el jugador Fila podría elegir Hablar con una probabilidad de 2/3 y Callar con una probabilidad de 1/3; diriamos entonces que está empleando una estrategia mixta. No obstante, podemos en el caso del DP quedar dispensados del engorro de tener que considerar estrategias mixtas y trabajar con probabilidades, puesto que no hay nuevos equilibrios de Nash para el juego cuando se usan estrategias mixtas. Esto obedece a que Callar está fuentemente dominada por Hablar y ningún jugador racional, en estas circunstancias, elegiria Callar con pro. babilidad positiva. Cf. Binmore, K., Teoria de juegos, p. 227. 
plicidad y convención (y dado que las situaciones posibles son cuatro), daremos el valor 4 al resultado más deseado por un jugador, y el valor de 1 al que menos grato le sea. Según lo expuesto en la Fig. 4, la situación preferida (valor 4) para Fila es que Columna respete las normas mientras él, por su parte, las incumple (casilla II). A continuación (valor 3) le interesa que ambos respeten las normas (casilla IV). Menos deseable (valor 2) le parece la circunstancia en que ambos incumplen las normas (casilla I). Y, con mucho, la situación menos preferida (valor 1) es que Columna infrinja las normas mientras él, Fila, las cumple. Damos por bueno que Columna tiene la misma escala ordinal de preferencias.

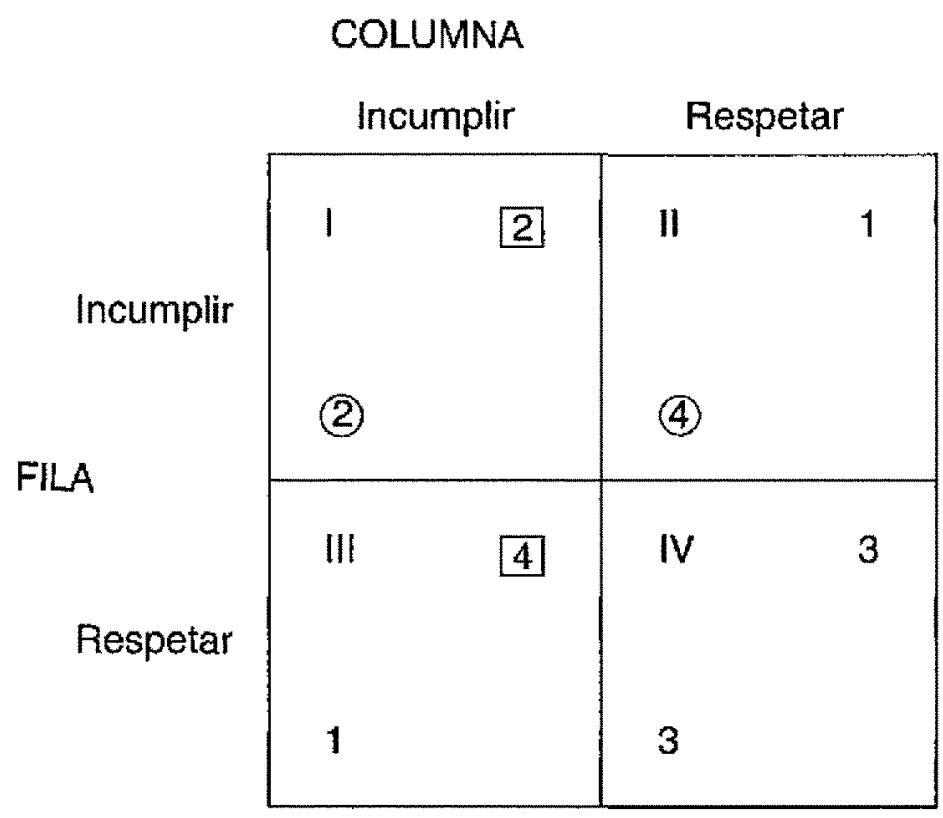

Fig. 4. El juego del parto social.

Nótese, antes de seguir, que en la nueva matriz de la Fig. 4 no sólo ocurre que los pagos están expresados ordinalmente, en lugar de cardinalmente (como en la Fig. 3); también sucede que los pagos de la Fig. 3 represantaban años de cárcel y que, en consecuencia, eran pagos a minimizar, mientras que los de la Fig. 4 representan niveles de bienestar y, por tanto, son pagos a maximizar. Hechas estas consideracioncs, se advierte que Fila y Columna, interesados en maximizar su bienestar personal, tienen como estrategia dominante incumplir las normas de convivencia, lo que precipita que la solución estable e ineficiente (subóptima) del juego sea de nuevo la casilla I, que representaría aproximadamente lo que Hobbes llamaba «estado de naturaleza». La casilla IV (que 
figuraría la civilización o paz social) es Pareto-superior al estado de naturaleza, y la manera de acceder a ella sería, como Hobbes advirtió agudamente, a través de un contrato social por el que los jugadores desistieran bilateralmente y al unísono de seguir su estrategia dominante.

Pero ahora es el momento de reparar en que si bien el estado de naturalcza (casilla 1) es un equilibrio ineficiente, la situación de civilización (casilla IV) es, inversamente, un óptimo de Pareto pero también una condición intrínsecamente inestable: un «inequilibrio» eficiente. Que es un óptimo de Pareto se sigue de que no hay otra situación -entre las tres restantes accesiblesque sea Pareto-superior a ella. Que no es un equilibrio de Nash se desprende del hecho de que cada uno de los jugadores quedaría mejor parado (pasaría del nivel 3 al 4 de bienestar) si cambiara por su cuenta de proceder, a condición, eso sí, de que el otro no lo hiciera. Pero, puesto que la otra parte pensará de la misma forma, lo probable es que ambos jugadores se apresten oportunistamente a violar el pacto social contraído, y regresen con ello al estado de naturaleza. Una reflexión semejante a ésta conducía a Hobbes a manifestar que «sin la espada los pactos no son sino palabras, y carecen de fuerza para asegurar en absoluto a un hombre» ${ }^{18}$. También de esta fragilidad del contrato social entre seres humanos egoístas y racionales infería Hobbes la necesidad de una institución, el Estado, con poder suficiente para obligar a las partes a cumplir los términos de lo acordado ${ }^{19}$.

\subsubsection{Conclusiones intermedias}

Al hacer un sumario de las características del DP básico (bipersonal, monoperiódico), nos encontramos con lo siguiente:

1. Cada jugador tiene una estrategia dominante, que es defectiva o insolidaria hacia el otro.

2. El uso de la estrategia dominante por parte de ambos jugadores conduce a un resultado estable y subóptimo.

3. El tránsito de la situación subóptima a otra que sea óptima requiere la colaboración pactada de ambos jugadores.

4. Esa colaboración, caso de producirse, es inestable. Se requiere, para volverla estable, la presencia de un agente coercitivo externo encargado de velar por la atinencia a lo pactado.

Estas peculiaridades del DP estático aclaran no sólo por qué se le ha tomado como modelo idóneo para ilustrar las dificultades de autoprovisión, por una sociedad civil, de bienes públicos y orden social, sino también como una corro-

"Hobbes, T., Leviatán, Madrid, Editora Nácional, 1983, p. 263.

${ }^{19}$ Para una exposición mucho más detallada del pensamiento de Hobbes a la luz de la teoría de juegos, se puede acudir a Taylor, M., The possibility of cooperation, pp. 126-150. 
boración de las intuiciones de Hobbes ${ }^{20}$. El orden social se tiene en general por deseable pero, librados a sí mismos, los individuos, cuando actúan como free-riders, parecen querer socavar su producción. Los acuerdos verbales y los buenos propósitos de abandonar voluntariamente el free-riding son intrínsecamente endebles (poco o nada creíbles), y precisan de un mecanismo externo que suministre exógenamente a las partes las garantías de observancia de lo socialmente convenido.

\subsection{Modelo dinámico bipersonal ${ }^{21}$}

\subsubsection{El superiuego DP bipersonal}

Si bien se puede construir el modelo dinámico del DP con la matriz de pagos de la Fig. 2, nos va a ser útil (y más intuitivo) reformular el juego de suerte que los pagos del mismo vengan expresados en términos cardinales y sean pagos a maximizar. Podemos inventarnos una módica historia ilustradora del juego, como la siguiente: dos socios, Fila y Columna, se unen para sacar adelante un negocio en común. Si ambos cooperan lealmente, ganará cada uno 3 millones de pesetas. Pero si uno de ellos colabora mientras el otro escurre el bulto,

${ }^{20}$ Mancur Olson, en The Logic of Collective Action, op. cit., fue el primero en obtener una exposición clásica de los problemas de provisión de bienes colectivos en un marco $N$-personal estático, pero emplea para ello el instrumental analítico de la teoría económica neoclásica (marginalista). Posteriormente, Hardin trasladará al lenguaje de la teoría de juegos los resultados de Olson (a la vez que someterá a revisión crítica algunos de ellos) en su obra Collective action, cit. Thomas Schelling llcva a cabo una exposición diagramática sencillamente magistral en «Hockey Helmets, Concealed Weapons, and Daylight Saving: A Study of Binary Choices with Externalities», Joumal of Conflict Resolution, 17 (3) (1973), pp. 381-428, artículo que luego se convertiría en el capitulo 7 de su libro Micromotives and Macrobehavior, Nueva York. W. W. Norton \& Company, 1978. Con razón se ha considerado el tratamiento de Schelling como el más penetrante, y a la par elegante, del DP N-personal; asi lo ve Margolis, H., Selfishness, Altruism and Rationalty, Chicago, The University of Chicago Press, 1984, p. 173. Quizá la novedad principal que aporta el estudio del caso $\mathrm{N}$-personal es que permite diferenciar dos umbrales: el umbral K de la cooperación independiente (en que $\mathrm{K}$ es el número minimo necesario para que a un participante potencial cualquiera le sea indiferente la cooperación en la acción colectiva a la inexistencia de la misma) y el umbral $L$ de las mejoras de Pareto (si hay menos de $L$ cooperadores, entonces todos salen. ganando con la generalización de la cooperación; cuando e] número de cooperadores es exactamente L, los no cooperadores obtienen con esta situación el mismo nivel de bienestar que el que todos tendrían en la situación de cooperación universal; a partir de $L$ un cooperante potencial entenderá que alcanza una satisfacción mayor en el caso de que más de $L$ jugadores cooperen y él defraude que en el caso de que todos, incluido él mismo, cooperen). Dados los umbrales $K$ y $L$, la estrategia de cooperar tiene sus mayores atractivos (sin dejar por cllo de ser una estrategia dominada) en el tramo entre K y L.

"Este apartado descansa en Axelrod, The evolution of cooperation, op. cit., $y$, en menor medida, en las obras de Taylor, M., Anarchy and Cooperation, Londres, John Wiley \& Sons, 1976, pp. 28-63, y the possibility of cooperation, op. cit., pp. 60-109. 
el que defrauda gana 5 millones y no queda nada para el otro. Y si ambos optan por el juego sucio, sólo se llevará cada uno 1 millón.

Las comprobaciones rutinarias nos certifican que se trata del Dilema del Prisionero: vemos que cada jugador tiene una estrategia dominante (Defraudar); que el uso de esa estrategia conduce, como solución del juego, a la casilla IV, que representa un equilibrio de Nash; que la solución del juego es ineficiente, en la medida en que hay otra casilla (la I en este caso) en la que tanto Fila como Columna mejorarían; que el tránsito a esta casilla Pareto-superior sólo es factible por la voluntad mancomunada de ambos jugadores $y$, por último, que ese tránsito, de producirse, es inestable.

Hemos mantenido los valores de los parámetros de pago de la Fig. 2, sólo que reacomodándolos para expresar la nueva situación ${ }^{22}$. La diferencia crucial con los modelos estáticos es que ahora permitiremos a Fila y Columna que jueguen distintas partidas o rondas del mismo juego a lo largo del tiempo. En teoría de juegos se llama superjuego a la repetición de un mismo «juego constituyente» como el representado en la Fig. 5.

Tanto el DP básico o constituyente de la Fig. 5 como el superjuego DP que se puede construir a partir de él por repeticiones del juego constituyente son juegos no cooperativos, en que o bien los acucrdos no son posibles 0 , si lo son, los jugadores no están constreñidos a cumplirlos. Es precisamente la posibilidad de cooperación en ausencia de tal constricción lo que nos interesa explorar. En la perspectiva dinámica del superjuego se incorpora un factor que no estaba presente en el DP básico y que fácilmente se comprende que es decisivo: cada jugador puede hacer ahora, si lo desea, que su decisión en una ronda del superjuego dependa de las elecciones que haya tomado el otro en las rondas precedentes. En otras palabras: puede hacer que su propia elección sea sensible a la historia del superjuego hasta ese momento. Esto hace que en el superjuego aparezca un elemento interno y tácito de coacción: a cada jugador le es posible ahora en una jugada cualquiera castigar las desviaciones de la cooperación que haya observado en el otro participante. Resulta intuitivo pensar que estas nuevas condiciones pueden favorecer la cooperación espontánea (sin el concurso de coacciones por agentes externos) y autosostenida, en la medida en que es razonable imaginar que Fila cooperará con su socio Columna si los beneficios futuros de la cooperación recíproca exceden las ventajas que se siguen de defraudar unilateralmente en una ronda del juego. Y lo mismo será cierto para Columna.

Lo primero que habremos de advertir es que esta incorporación del tiempo al estudio de la cooperación social, bajo la forma de repetición sucesiva de

${ }^{22}$ Los parámetros de pago pueden tomar muy distintos valores, pero no cualesquiera. Tanto Axetrod como Taylor imponen a tales valores la condición de que la recompensa por cooperación mutua exceda la mitad de la suma del pago por defección unilateral y el pago por cooperación unilateral. Es evidente que las cifras que aparecen en la Fig. 5 cumplen esta condición. La importancia de este requisito quedará clara más adelante. 
COLUMNA

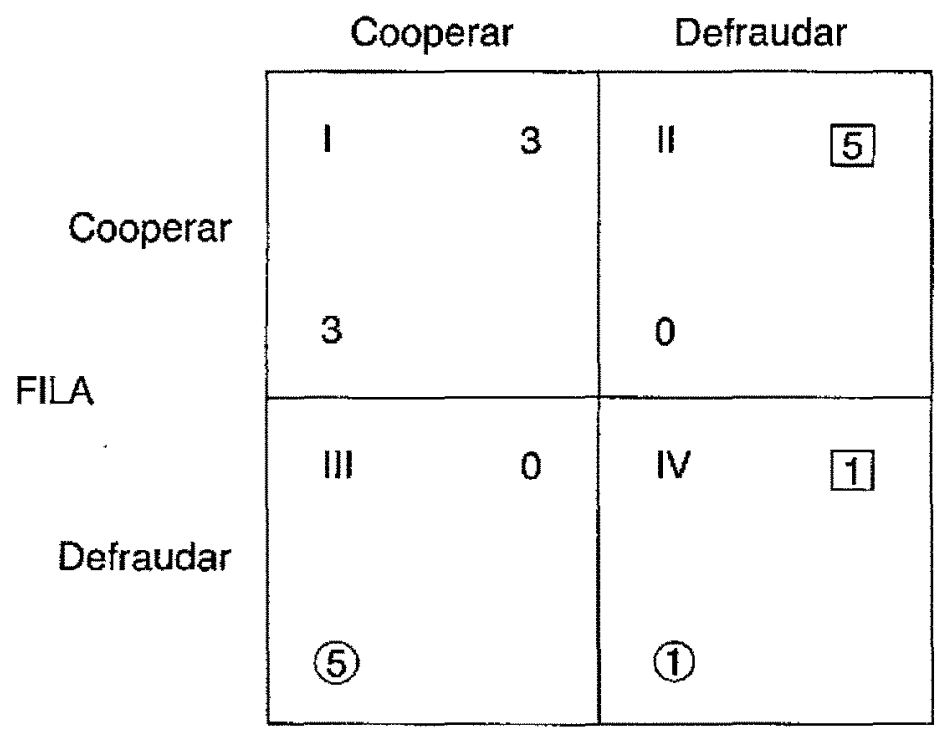

Fig. 5. El DP con pagos cardinales a maximizar.

la misma situación de interacción, dota de mayor realismo a los modelos n-periódicos (dinámicos) sobre los monoperiódicos (estáticos). Efectivamente, los encuentros con una misma persona, en los que es dable cooperar o defraudar, se pueden reiterar indefinidamente en el tiempo, siendo ésta una situación muy frecuente en la vida cotidiana. Yo suelo ir, por ejemplo, a comprar fruta a un mismo puesto en el mercado, y es así como actúa la mayor parte de la gente. Hay una buena razón para ello: estoy haciendo patente al vendedor que no le defraudo, y que así seguirá siendo mientras él, por su parte, no me defraude a mí con la mercancía. Es decir, cada uno coopera de manera condicional con el otro, y de este modo el frutero se asegura mi «lealtad» y yo me aseguro su shonestidad» ${ }^{23}$. La perspectiva de una secuencia indefinida de encuentros venideros disuadirá a cada una de las partes de quebrantar

${ }^{24}$ Claro está que estas cualidades, tal y como han sido descritas, no son cualidades morales (de ahí las comillas), sino fundadas en el interés de las partes. Para convertirse en cualidad moral la honcstidad del tendero habría de estar anclada en controles internos, ligados a su autoimagen; esto es, sólo habria tal honestidad moral si el tendero se ve a sí mismo como la «clase de persona» que no da gato por liebre a un cliente aunque pudiera hacerlo impunemente, y esto porque su ética profesional (o su conciencia motal tout court) se lo impediria o pondría muy costoso, en términos de malestar de conciencia. Consideraciones parecidas se podrian hacer con respecto a mi lealtad como comprador. 
la confianza en el otro ${ }^{24}$. La cooperación, en estos encuentros bilaterales, se sostendrá por la amenaza implícita de "responder con la misma moneda» si nos sentimos decepcionados con el proceder de la otra parte.

Habrá que suponer, por lo demás, que el valor que para una persona puedan tener las remuneraciones o «pagos» que se deriven de encuentros futuros con otra será inferior al valor que tiene un pago de la misma cuantía pero que se acaba de percibir. Entenderemos, dicho de otra forma, que los pagos pierden valor a medida que su percepción se aleja en el futuro, por más que su magnitud nominal sea la misma. De esta manera, el valor que, en el momento presente, tiene el pago por cooperación mutua en la ronda $24^{\mathrm{a}}$ del superjuego DP será inferior, para Fila o Columna, al valor que ese mismo pago tiene en la ronda $16^{a}$, y éste, a su vez, estará por debajo del que tiene esa cooperación mutua en la ronda $3^{\mathrm{a}}$, etc.

En su afán de concreción y claridad, los especialistas en teoría de juegos efectúan los siguientes supuestos sobre los pagos y su recepción:

i) Cada juego constituyente de un superjuego DP scrá jugado a intervalos regulares y discretos de tiempo, uno en cada período.

ii) El superjuego empieza en cl período $\mathrm{n}=1$, y los pagos son efectuados en $\mathrm{n}=1,2,3 \ldots{ }^{25}$

iii) Los pagos futuros (los percibidos a partir del período $n=2$ ) están afectados por un factor de descuento d, que toma valores cntre 0 y $1(0<\mathrm{d}<1)$. Para entender la incidencia del factor de descuento (o parámetro de actualización, como lo llama Axelrod), lo mejor será poner un sencillo ejemplo numérico. Imaginemos que un individuo va a recibir 1.000 pesetas cada mes a partir del instante presente y durante medio año. En primer lugar, está claro que 1.000 pesetas hoy valen más que 1.000 pesetas dentro de medio año, y eso incluso en ausencia de inflación. El perceptor de los pagos puede invertir inmediatamente las 1.000 pesetas obtenidas hoy y ponerlas a producir intereses,

${ }^{24}$ De nuevo, la confianza que aquí se menciona carece de valor moral. Se trata más bien del subproducto (en el sentido de Elster) de interacciones continuadas entre dos personas, ninguna de las cuales ha defraudado a la otra. En cambio, si confias moralmente en otro no es únicamente porque no te haya defraudado en el pasado, sino porque sabes que no te puede defraudar; es decir, porque esa persona está sometida a autorrestricciones morales (que uno conoce) y que le vedan la posibilidad de decepcionar a otro. La diferencia crítica (en términos de conducta observada) parece estar en lo sjguiente; si yo confío amoralmente en alguien, dejaré de confiar en él cuando tenga con ese alguien la última interacción, y ambos scpamos que es la última. $\mathrm{Si}$, por el contrario, confío moralmente en esa persona, entonces estaré seguro de que no me la jugará incluso cuando sea conocimiento común que no nos veremos más en el futuro; y mo basaré, para tener esta seguridad, no sólo en las preferencias reveladas en su conducta (aunque también en esto), sino sobre todo en mi conocimiento de sus metapreferencias, es decir, en mi percepción del tipo de persona que él aspira a ser.

${ }^{25}$ Hay aquí una pequeña diferencia - no significativa - en los análisis de Axelrod y Taylor. Para Taylor, los pagos se eféctúan al final de cada período y, por tanto, no hay ningún pago no afectado por el factor de descuento. Para Axelrod, en cambio, el primer pago de cada serie no está descontado. Seguiremos aquí el criterio de Axelrod. 
con lo que serán más de 1.000 al cabo de medio año. También los pagos futuros se ven negativamente afectados por la incertidumbre, quizá pequeña pero significativa, acerca de si desaparecerá repentinamente la generosa fuente de financiación, o si uno mismo, como receptor de la corriente de pagos, seguirá con vida durante los próximos meses o estará criando malvas... Todas estas consideraciones mueven al individuo a estimar que el valor presente que tiene para él el flujo de pagos que se le ha prometido es como aparece en el cuadro 1.

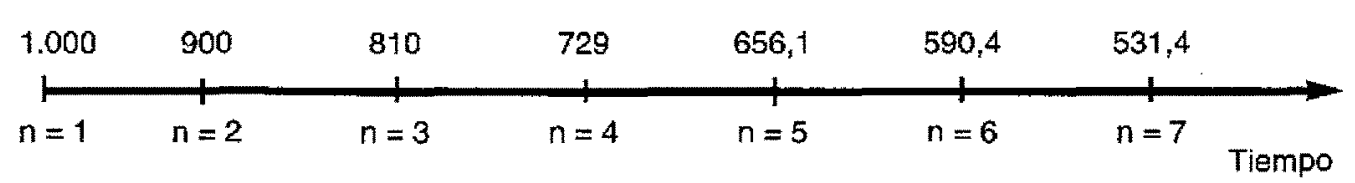

Cuadro 1. Valor presente de una corriente de pagos.

El factor de descuento que aplica el individuo es $\mathrm{d}=0,9$, y decrece exponencialmente. Es decir, el valor que ticnen, en el período $\mathrm{n}=1,1.000$ pesetas que se van a recibir en el período $n=2$ será de $1.000 \times 0,9=900$. Dicho de otro modo: 900 pesetas hoy valen lo mismo para él que 1.000 a percibir en el período (mes) síguiente. El valor de esas 1.000 pesetas dentro de dos meses $(n=3)$ será $1.000 \times(0,9)^{2}=810$, etc. El valor presente de esa corriente de pagos se obtiene sumando los valores descontados de cada período.

$$
\begin{aligned}
& \text { Valor presente }=1.000+900+810+729+656,1+590,4+531,4= \\
& =5216,9
\end{aligned}
$$

Nótese que es razonable suponer que el factor de descuento no toma los valores extremos 1 ó 0 . Si d $=1$, entonces los pagos futuros no sufrirían ninguna depreciación y el valor presente del flujo de pagos de los siete períodos sería de 7.000 pesetas. $\mathrm{Si} d=0$, entonces los pagos futuros no valen nada para el individuo. En el seno de un superjuego DP, que ambos jugadores consideren que $d=0$ equivaldría a rcducir el superjuego al juego constituyente.

iv) Volviendo al superjuego DP de los socios Fila y Columna cuyo juego constituyente está consignado en la Fig. 5, los teóricos de juegos adoptan el supuesto (desde luego, poco realista) de que, a la hora de decidir en el instante actual la estrategia a adoptar, los jugadores tienen en cuenta el valor presente de la corriente entera de pagos que se derivaría de emplear esa estrategia a lo largo del superjuego frente a la estrategia del otro participante. (El sentido de esta afirmación quedará más claro enseguida.) 


\subsubsection{Los tomeos de Axelrod}

Hacia finales de la década de los 70 , el politólogo Robert Axelrod convocó a un grupo de entendidos en teoría de juegos para participar en un Torneo sobre el superjuego DP bipersonal. Los concursantes procedían de campos como la economía, la psicología, las ciencias políticas y las matemáticas. Se presentaron en total 14 programas o estrategias para abordar el superjuego DP, más un decimoquinto programa, llamado AZAR, que coopera o no aleatoriamente y con la misma probabilidad. Cada programa especificaba lo que había que hacer en cada momento del superjuego, teniendo o no en cuenta (a voluntad) lo que hasta entonces había sucedido y, en especial, si el oponente había cooperado o defraudado.

Se anunció a los concurrentes que el Torneo se desarrollaría en forma de liga: cada uno contra todos los demás en partidas en que se enfrentarían dos participantes cada vez. También se les dijo que cada programa se enfrentaría con su gemclo exacto y con AZAR. Cada superjuego entre dos programas constaría de 200 jugadas ( $\mathrm{y}$ ambos jugadores conocían este hecho), con una matriz de pagos como la presentada en la Fig. 5. Dada esta matriz, el máximo que podía alcanzar una estrategia (programa) jugando con otra 200 veces seguidas eran 1.000 puntos; tal cosa sucedería en el improbable caso de que fuera una estrategia que defraudara siempre y estuviera enfrentándose a una estrategia que cooperara incondicionalmente. El mínimo eran 0 puntos. En la práctica, las puntuaciones oscilaron cntre 200 y 600 puntos. El Torneo lo ganó la estrategia TIT-FOR-TAT (TFT, en adelante), presentada por el profesor de la Universidad de Toronto (Canadá) Anatol Rapoport. TFT alcanzó una media de 504 puntos en cada superjucgo y era, además, el más sencillo de todos los programas presentados. TFT empieza cooperando, y a partir de ahí hace en cada jugada lo que el otro jugador haya hecho en la precedente. Otras reglas posibles de fácil descripción para jugar el superjuego DP (pero que no se presentaron a este Torneo) son:

SIEMPRE D: defrauda siempre, haga lo que haga el otro.

REPRESALIA PERMANENTE: empieza cooperando y continúa haciéndolo hasta que el otro defruada por primera vez. Desde ese momento no coopera nunca más.

DCDC: defrauda y coopera alternativamente, empezando por una defección.

Para hacernos una idea más plástica de lo que sería un superjuego de este Torneo, imaginemos que el jugador Fila emplea TFT y el jugador Columna, SIEMPRE D. Sea d el factor de descuento, C la opción de cooperar y D, la de defraudar. Sean también $\mathrm{CC}=3$ el pago por mutua cooperación; $\mathrm{DD}=1$, el pago por mutua defección; $\mathrm{CD}=0$, el pago por cooperación unilateral; 
y $\mathrm{DC}=5$, el pago por defección unilateral. Supongamos, para mayor generalidad, que el superjuego se juega n veces, no necesariamente 200.

\begin{tabular}{|c|c|c|c|c|c|}
\hline & Periodo 1 & Pcriodo 2 & Perioda 3 & .............. & Periodon \\
\hline $\begin{array}{l}\text { FILA } \\
\text { (TFT) }\end{array}$ & $c$ & $\mathrm{D}$ & $\mathrm{D}$ & ........... & $\mathrm{D}$ \\
\hline $\begin{array}{l}\text { COLUMNA } \\
\text { (SIEMPRE D) }\end{array}$ & D & D & $D$ & …........ & D \\
\hline $\begin{array}{l}\text { PAGOS PARA } \\
\text { FILA }\end{array}$ & $\mathrm{CD}=0$ & $\mathrm{~d} \times \mathrm{DD}=\mathrm{d}$ & $d^{2} \times D D=d^{2}$ & $\ldots \ldots \ldots$ & $d^{n-1} \times D D=d^{n-1}$ \\
\hline
\end{tabular}

Cuadro 2. TFT contra SIEMPRE D.

El valor presente de esta corriente de pagos [al que llamaremos V(TFT/SIEMPRE D)] es $0+d+d^{2}+\ldots+d^{n-1}$. Al tratarse de la suma de los términos de una progresión geométrica decreciente ${ }^{26}$, tenemos que V(TFT/SIEMPRE D $)=d /(1-d)$.

¿Y qué es lo que obtiene Fila si es él el que emplea SIEMPRE D y se enfrenta a Columna, que emplea TFT?

V(SIEMPRE D/TFT $)=5+\mathrm{d}+\mathrm{d}^{2}+\ldots+\mathrm{d}^{\mathrm{n}-1}=5+\mathrm{d} /(1-\mathrm{d})$

Es evidente, entonces, que V(SIEMPRE D/TFT) $>$ V(TFT/SIEMPRE D), sea cual fuere el valor que adopte el factor de descuento. Se puede incluso llegar un poco más lejos, y demostrar que TFT pierde o, a lo sumo, empata en una confrontación singular con otra regla cualquiera; lo cual tampoco sorprende cuando se toma en consideración que TFT coopera tantas veces como coopera el adversario, o una más, y defrauda tantas veces como defrauda el adversario, o una menos. ¿Cómo es posible que, siendo esto así, TFT fuera la triunfadora en el Tornco de Axelrod? La respuesta está en que hay una diferencia crucial entre el Torneo de Axelrod y, digamos, una liga de fútbol. El fútbol es un jucgo de suma cero, en que los intereses de los contendientes son contrapuestos; esto hace que una liga de fútbol la gane el equipo que haya perdido menos partidos y/o haya ganado más. Esto no es cierto en un Torneo de Axelrod, puesto que el DP no es un jucgo de suma cero, sino uno en que los intereses de las partes no son estrictamente antagónicos y tiene mucho sentido la mutua cooperación. En un Torneo de Axelrod puede

${ }^{26}$ Recuérdese que la suma de los $n$ términos de una progresión geométrica decreciente es igual a $a_{1} /(1-r)$, siendo a el primer término de la progresión, y, la razón de la progresión, es decir, el factor que, multiplicado por un término cualquiera de la serie, nos proporciona el siguiente. Que es una progresión geométrica decreciente significa que la razón de la progresión (que en muestro caso es el factor de descuento) toma valores entre 0 y 1 . 
darse el caso de que venza una estrategia que jamás ha ganado un solo superjuego "contra» otra estrategia; tal cosa es factible porque, a diferencia de lo que sucede con una liga de fútbol, a una estrategia no le interesa vencer a otra sino más bien obtener buenos resultados con una gran variedad de estrategias; y para obtener tales resultados interesará a una estrategia estimular la cooperación con sus contendientes, más que la mutua defección (a la vista de que $C C>D D$ ). Ahora bien, si las dos partes cooperan, ninguna gana; de modo que el objetivo no es tanto derrotar a cada adversario que por turno se nos presente, sino conseguir el máximo de cooperación y el mínimo de defección recíprocas con cada uno de ellos.

¿Qué virtudes atesora la estrategia TFT para lograr tan cumplidamente cste objetivo y erigirse en vencedora del Torneo de Axelrod?

I) Es una estrategia amable. Son estrategias amables aquellas que nunca son las primeras en no cooperar (la estrategia DCDC, p. ej., no es amable). Es muy de notar que las ocho reglas que quedaron clasificadas en los primeros puestos en el Torneo de Axelrod eran amables.

Puesto que en un superjuego de 200 jugadas y con $\mathrm{CC}=3$, cada regla amable alcanza 600 puntos al interactuar con otra regla amable, el éxito relativo en el Torneo de unas reglas amables sobre otras vino determinado por la puntuación que estas reglas obtuvieron al vérselas con las reglas no amables. Las cualidades que hacen que una regla amable salga bien parada de su encuentro con otra regla no amable son:

II) Indulgencia o disposición a perdonar una defección al contrario y seguir cooperando con él.

III) Vindicatividad o talante de responder a la defección con la defección, de manera inmediata y segura.

TFT es, a la vez, vengativa e indulgente: no perdona ninguna defección y paga con la misma moneda (de modo que no es fácilmente explotable); pero también es indulgente, y se olvida de las malas pasadas del otro. Diciéndolo en términos bíblicos, TFT es «pronta en la cólera pero rica en piedad». Con estas propiedades, cuando pierde frente a una regla no amable lo hace por un margen muy estrecho. Por otra parte, estrategias amables pero vengativas, como TFT, impiden eficazmente que prosperen las reglas poco amables: una regla no amable perjudica a TFT, pero difícilmente sale ella beneficiada.

IV) TFT es una estrategia clara o fácilmente reconocible por las demás reglas, y eso debido en parte a su misma simplicidad. En contraste con lo que sucede en los juegos de suma cero, en que es útil mantenerse en la estricta reserva y no dar a conocer nuestra estrategia al contrario, en los juegos de suma no nula puede ser en ocasiones de conveniencia para nosotros que la otra parte nos entienda desde el principio y pueda predecir correctamente lo que vamos a hacer en respuesta a cada uno de sus posibles movimientos. De esta forma, su conducta puede acomodarse a la nuestra en la dirección de la cooperación, y para la obtención y reparto de los frutos de la misma. 
Por supuesto, el otro ha de entender no sólo qué haremos nosotros si él coopera, sino también qué le cabe esperar si no coopera. TFT transmite un mensaje claro en ambos respectos.

V) TFT es robusta. Se planteó en seguida la cuestión de si TFT habría obtenido el mismo éxito de enfrentarse a un grupo de estrategias diferente. Para despejar esta duda (esto es, para averiguar si TFT era robusta), se preparó un segundo Torneo. Los concursantes de éste fueron puestos al corriente de los resultados del primero. Se presentaron ahora 62 programas, a los que se sumó de nuevo la regla AZAR. A diferencia del primer Torneo, los jugadores desconocían aquí el número de jugadas de que constaría cada superjuego, número que osciló entre un mínimo de 63 y un máximo de 308 , con una media de 151 jugadas. Se estableció esta incertidumbre para esquivar los efectos distorsionadores sobre la cooperación que introduce la certeza de cuándo concluirá el superjuego.

Para entender esto último, supongamos que un superiuego está planeado a seis partidas. Sabido esto por ambos jugadores, está claro que en la sexta jugada sus estrategias respectivas fijarán la opción de Defraudar, ya que no hay cabida para represalias ulteriores por la otra parte. Luego Fila y Columna, al saber que la sexta será la última jugada, saben tambiến que jugarán a Defraudarse el uno al otro en ella. Pero esto también significa que, a efectos estratégicos, la quinta (penúltima) jugada es ahora como si fuera la última, y de nuevo no tendrá scntido para ninguno de los dos cooperar cuando saben que cn la sexta jugada es seguro que van a Defraudar; cada uno clcgirá Defraudar también en la quinta para sacar ventaja en el último momento. Por razones similares, Defraudar será también la estrategia dominante en la cuarta jugada, en la tercera, etc. Razonando por inducción hacia atrás, tanto Fila como Columna concluirán que hay que empezar no cooperando ya desde la primera jugada ${ }^{27}$.

La vencedora del segundo Torneo fue de nuevo TFT, presentada otra vez por Anatol Rapoport. Esta parece una prueba sobresaliente de la robustez de TFT pero, no contento con esto, y como forma adicional de confirmar esa robustez, Axclrod simuló mediante ordenador rondas futuras del segundo Torneo, haciendo que en cada ronda sobrevivieran y estuvieran más representadas aquellas reglas que hubieran obtenido un éxito mayor en la ronda previa, y fueran eliminadas o tuvieran un papel cada vez menor aquellas otras reglas que hubieran obtenido resultados más mediocres. Una forma obvia de calcular la representación podría ser ésta: si la regla $\mathrm{A}$ ha obtenido el doble de puntuación (en promedio) que la regla $B$ en la ronda $n$, eso va a significar que A será asumida por el doble de individuos que $B$ en la ronda $n+1$.

${ }^{27}$ Véasc Luce, D., y Raiffa, MI., Games and Decisions, John Wiley \& Sons, 1957, pp. 989. David Kreps et alia, en «Rational Cooperation in the Finitely Repeated Prisoners' Dilemma» [Joumal of Economic Theory, 27 (1982), pp. 245-252] han probado que este resultado deja de ser válido si los jugadores tienen dudas acerca de las motivaciones, opeiones de conducta o pagos de los otros coparticipantes. 
De esta manera se va alterando el ambiente en el que se mueven las reglas, y cada regla superviviente se tiene que ir enfrentando en las sucesivas rondas con otras reglas que han probado también sus excelentes aptitudes para sobrevivir y prosperar.

Esta simulación «ecológica» guarda un fuerte parecido con la selección natural de los más aptos. No cuesta nada imaginar cada ronda como una generación, en que los individuos con mayor éxito adaptativo dejarán más copias o descendientes de sí mismos en la generación siguiente. El parecido entre la selección natural y la simulación ecológica del segundo Torneo se quiebra, entre otras cosas, porque en esta última no se prevé la aparición de estrategias mutantes. El entorno de las reglas evoluciona mediante el incremento diferencial en la representación de las reglas más cualificadas dentro del acervo de reglas existentes desde un principio. No se introducen reglas nuevas en alguna de las rondas posteriores.

Los resultados de esta simulación ecológica muestran que las estrategias que basan su supervivencia en la explotación de las debilidades de otras reglas tienen un porvenir oscuro, puesto que las reglas más explotables van representando una proporción cada vez menor del entorno en las rondas sucesivas; las reglas depredadoras, podríamos decir, erosionan la base de su éxito, con lo que aceleran su propia eliminación. Sobrevivir pasa a significar, cada vez más, tener éxito sin menoscabar para ello el éxito de los otros. Esto vale tanto como afirmar que las estrategias cooperantes tienen un futuro más risueño en esta simulación ecológica, en la que, de nuevo, salió victoriosa TFT.

VI) TFT es una estrategia colectivamente estable. Para entender este concepto, diremos primero que una cstrategia $\mathrm{A}$ invade a una población formada por jugadores que emplean la estrategia $B$ si $V(A / B)>V(B / B)$, es decir, si un colono $A$ obtiene con un nativo $B$ mejores resultados que los que los nativos $B$ alcanzan al interactuar entre ellos. Una estrategia $B$, diremos ahora, es colcctivamente estable si no existe ninguna estrategia capaz de invadirla ${ }^{28}$.

Para entender mejor este concepto, volvamos a la simulación «ecológica», pero permitamos ahora la aparición de estrategias mutantes. Imaginemos, por añadidura, una población en la que todos sus miembros emplean TFT ${ }^{29}$. Sabe-

${ }^{3 x}$ Otra forma de definir una estrategia colectivamente estable es afirmar que es aquella estrategia que estâ en equilibrio de Nash consigo mismo; esto es: cualquier individuo que se aparte unilateralmente de la estrategia prevaleciente en una poblaciốn y adopte cualquier otra estrategia distinta alcanza unos pagos medios inferiores. Esta noción guarda muy estrecha relación con la de estrategia evolutivamente estable empleada por el biólogo John Maynard Smith. Véase su Evolution and the Theory of Games, Cambridge, Cambridge U. P., 1982, pp. 10 y passim.

* Axelrod, como se ve, simplifica la descripción identificando a un individuo con una estrategia de conducta, pero no cabe duda que sería más ajustado a los hechos concebir a un individuo como un repertorio de estrategias posibles, de las que en cada caso (y atendiendo a circunstancias del entorno $y$, señaladamente, a con quién interactúa en determinado momento) actualiza una de ellas. Los hábitos adquiridos, la educación recibida y su propia experiencia y capacidad racional harán que algunas de las reglas de su repertorio tengan una probabilidad sensiblemente mayor de ser usadas por él. Seria, a mi cntender, lícito definir el carúcter de una persona como la 
mos ya que una cstrategia mutante invadirá la población TFT si el mutante logra, en sus encuentros con los nativos TFT, remuneraciones más altas que las que los nativos alcanzan en sus contactos entre sí. (Hay que hacer notar, entre paréntesis, la siguiente asimetría: el mutante se encontrará siempre con individuos TFT, y no con individuos que emplean la cstrategia mutante, mientras que los nativos TFT tendrán una probabilidad muy alta de tropezarse con otros nativos TFT y una probabilidad muy pequeña de hacerlo con el mutante. Naturalmente, en la medida en que el mutante tenga éxito e invada la población nativa, estas probabilidades se irán alterando.) ¿Se dejará invadir una población TFT por una estrategia mutante? Pensemos que en una población TFT cada individuo recibe un pago $\mathrm{CC}=3$ por jugada y también en promedio. Para obtener un pago promedio superior a 3 es condición necesaria, pero no suficiente, defraudar siquiera una vez. No cs condición suficiente porque sabemos que TFT devuelve en seguida golpe por golpe $y$, al entrar en las represalias, es más que probable que el mutante alcance con TFT una puntuación inferior a la que un individuo TFT obtiene con otro que emplca la misma regla, en cuyo caso la regla mutante no invadirá la población. Por tanto, si los participantes creen que el superjuego durará lo suficiente después de la defección del mutante y si emplean un factor de descuento lo bastante clcvado, una población TFT no podrá ser invadida, pues la ganancia ocasional de $\mathrm{DC}=5$ para el mutante quedará sepultada por la defección recíproca posterior.

Para entender la importancia de que sea alto el valor del factor de descuento, supongamos que la estratcgia mutante potencialmente invasora fuera SIEMPRE D y que el valor de $\mathrm{d}=0,9$. Con los valores de los parámetros de pago como en Fig. 5, tenemos que

$$
\begin{gathered}
\text { V(TFT/TFT })=3+3(0,9)+3(0,9)^{2}+\ldots=3 /(1-0,9)=30 \\
\text { V(SIEMPRE D/TFT })=5+0,9+(0,9)^{2}+(0,9)^{3}+\ldots=5+0,9 /(1-0,9)= \\
=14
\end{gathered}
$$

En estas condiciones, SIEMPRE D no podrá invadir una población TFT. Pero imaginemos ahora que la importancia del futuro decae en la estimación de los intervinientes en el juego y $\mathrm{d}=0,3$. En este caso,

$$
\begin{aligned}
& \mathrm{V}(\text { TFT } / \text { TFT })=3 /(1-0,3)=4,28 \\
& \mathrm{~V}(\text { SIEMPRE D } / \text { TFT })=5+0,3 /(1-0,3)=5,42
\end{aligned}
$$

Ahora sí TFT deja de ser una estrategia colectivamente estable, y se torna vulnerable a la invasión por SIEMPRE D. Hay en general dos formas (no excluyentes entre sí) de conseguir un incremento en el valor del factor de descuento tal que TFT repela las invasiones:

distribución de probabilidad con que emplea las diferentes estrategias de conducta de su repertorio ante las diversas situaciones que se le puedan presentar. 
i) Hacer más duraderas las interacciones

ii) Hacerlas más frecuentes.

Una manera obvia de incrementar la frecuencia de las interacciones entre dos individuos consiste en aislarlos del resto, y limitar así el número de jugadores con los que puede relacionarse un jugador dado. Esto explicaría por qué es más fácil que emerja y sea estable la cooperación en pequeños núcleos de población que en las grandes ciudades. En los primeros, la cantidad de personas con las que tiene tratos un mismo individuo es mucho más reducida, lo que hace que la frecuencia de los encuentros con una persona dada sca más alta y resulten, con cllo, más firmes las bases de la cooperación. En las grandes urbes, por contraste, es a la vez más racional y más fácil mostrarse insolidario.

El optimismo que rezuma la aseveración de la estabilidad colectiva de TFT con factores de descuento elevados habrá de ser prontamente atemperado, pues hay que saber que la estrategia SIEMPRE D es también colectivamente estable, y además lo cs cualquiera que sea el valor que adopte el factor de descuento. No es difícil entender por qué una población SIEMPRE D no podrá verse invadida por ninguna estrategia diferente: si la estrategia es diferente, eso significará que el forastero o mutante coopera al menos una vez al encontrarse con un nativo SIEMPRE D, por razón de lo cual éste recibirá un pago $\mathrm{DC}=5 \mathrm{y}$ el otro un pago $\mathrm{CD}=0$, sin tener el intruso ocasión para desquitarse en el futuro, pues el usuario de SIEMPRE D no va a cooperar nunca. Así pues, en un mundo shobbesiano" de desaprensivos nadie venido de fuera con actitudes conciliadoras puede esperar salir bien librado.

Esta afirmación se sostiene si los colonos cooperantes llegan de uno en uno, pero puede dejar de serlo si acuden agrupados. Veamos de nuevo un pequeño ejemplo numérico. Los valores de los parámetros de pago son los habituales, y sea $d=0,9$. Según esto,

$\mathrm{V}($ SIEMPRE D/SIEMPRE $\mathrm{D})=1+\mathrm{d}+\mathrm{d}^{2}+\ldots=1 /(1-\mathrm{d})=$ $=1 /(1-0,9)=10$

A su llegada, un colono TFT se encontrará con seguridad sólo con nativos SIEMPRE D, y con cada uno de ellos alcanzará

$$
\mathrm{V}(\text { TFT/SIEMPRE } \mathrm{D})=0+\mathrm{d}+\mathrm{d}^{2}+\mathrm{d}^{3}+\ldots=\mathrm{d} /(1-\mathrm{d})=0,9 / 0,1=9
$$

Con lo que ningún colono aislado TFT podrá ínvadir una población SIEMPRE D. Sin embargo, se recordará que cuando un individuo TFT trata con otro de igual adscripción y $\mathrm{d}=0,9$, ambos alcanzan una puntuación $\mathrm{V}(\mathrm{TFT} / \mathrm{TFT})=30$. Si los colonos TFT llegan agrupados, podrán interactuar entre sí y alcanzar en esas interacciones 30 puntos, resultado muy superior a los 9 puntos que logran si se encuentran con un nativo SIEMPRE D, y también superior a los 10 puntos que obtienen los nativos SIEMPRE D en su trato mutuo. La cuestión es cuál es la proporción exacta, con relación al total de encuentros, con que habrán de verificarse las interacciones entre colonos 
TFT para contrarrestar los malos dividendos obtenidos con nativos SIEMPRE $D$, de suerte que quede sobrepujada la puntuación que los SIEMPRE D logran entre sí. Sea p la probabilidad con que un TFT se tropieza con otro TFT, y 1-p la probabilidad con que un TFT se tropieza con un SIEMPRE D. Queremos saber el valor de $\mathrm{p}$ para que

$$
30 p+9(1-p)>10 \quad(A)
$$

Haciendo las manipulaciones algebraicas pertinentes, resuita que $p>1 / 21$. Es decir, bastaría con que los TFT interactuaran entre sí un 5 por 100 de las veces para que, agrupados, pudieran conquistar una población SIEMPRE $\mathrm{D}^{30}$. Se dice entonces que un p-racimo ( $p$-cluster) de TFT invade a una población SIEMPRE D si PRE D),

$$
\mathrm{pV}(\mathrm{TFT} / \mathrm{TFT})+(1-\mathrm{p}) \mathrm{V}(\mathrm{TFT} / \mathrm{SIEMPRE} \text { D) }>\mathrm{V}(\mathrm{SIEMPRE} \text { D/SIEM- }
$$

siendo p la proporción de interacciones que los TFT mantienen entre sí.

Hay que notar que no se está diciendo que una invasión con éxito de colonos TFT requicra que los foráneos supongan un 5 por 100 con respecto a la población nativa SIEMPRE D, sino sólo que la frecuencia de las interacciones de los colonos entre sí sea al menos aproximadamente un 5 por 100 del total de las interacciones de los colonos. Pudiera suceder que los colonos invasores supusieran un 2 por 100 de la población nativa, pero que la relación entre cllos sea tan intensa que alcance el 5 por 100 del total de sus interacciones; pues bien, en tal caso conquistarán a los inhóspitos nativos.

Si una población SIEMPRE D puede verse invadida por un p-racimo de colonos que emplean una regla amable, como TFT, se suscita la cuestión simétrica de si una población usuaria de una regla amable que no pudiera ser invadida por colonos aislados que emplean una regla no amable, podría, no obstante ello, resultar conquistada por un p-racimo de tales colonos. La respuesta es que no ${ }^{31}$.

30 En realidad, si somos escrupulosos, tendríamos que rehacer la inecuación (A) para reconocer que los nativos obtendrán una puntuación promedio algo superior a 10 debido a sus interacciones muy esporádicas con los miembros del diminuto grupo de invasores. De hecho V(SIEMPRE $\mathrm{D} / \mathrm{TFT})=5+\mathrm{d} /(1-\mathrm{d})=5+0,9 / 0,1=14$. Pero aquí consideraremos despreciable la elevación del promedio inducida por estos encuentros poco probables.

${ }^{31}$ La Proposición 7 del libro de Axelrod reza: «Si una estrategia amable no puede ser invadida por un único individuo, tampoco podrá ser invadida por un racimo de ellos» (p. 214). El desglose de la prueba podría ser ếste:

- Supongamos que $B$ es amable y $A$ no lo es. inicial).

- Supongamos también que un individuo A no es capaz de invadir la población B (hipótesis

- Supongamos, además, y contra lo que queremos demostrar, que un p-racimo de $\mathrm{A}$ invade la población $B$ (hipótesis subsidiaria).

- Esto significa que $p V(A / A)+(1-p) V(A / B) \times V(B / B)$

- Como $B$ es amable, tenemos que $V(B / B)=C C /(1-d)$.

- Como A no es amable, al interactuar consigo misma obtendrá el pago $\mathrm{CC}$ en algunas ocasiones y el pago $D D$ en otras, por lo que $V(A / A) \times V(B / B)$.

- Dado que $V(A / A)$ ، $(B / B)$, A sólo podrá invadir la población $B$ en racimo si $V(A / B), V(B / B)$. 
Podemos ya reconstruir racionalmente la evolución de la cooperación, es decir, podemos explicar cómo pudo surgir y desarrollarse la cooperación desde un escenario inicial de defección incondicional ${ }^{32}$ :

A. Partimos de una situación hipotética con una población SIEMPRE D: éste sería el estado de naturaleza hobbesiano.

B. Aparece un grupo de individuos con una estrategia mutante basada en la cooperación condicional. Si la interrelación interna del grupo supera una cierta frecuencia relativa crítica, la estrategia de cooperación condicional TFT desplazará paulatinamente a SIEMPRE D.

C. TFT también prevalecerá en escenarios más diversificados, en que el ambiente esté formado por otras reglas además de SIEMPRE D. Debido a su extraordinaria robustez, TFT predominará incluso en entornos en que estén presentes otras reglas amables.

D. Una vez afianzada como regla mayoritaria de una población, TFT es indesbancable, ya que es capaz de repeler agrupamientos muy numerosos de reglas mutantes, y eso en virtud de su descollante estabilidad.

\subsubsection{Conclusiones intermedias}

La incorporación de la dimensión temporal al análisis de la provisión de bienes públicos mediante el DP hace que las perspectivas de emcrgencia espontánea y estabilidad de la cooperación sean notoriamente más halagücñas que las que se derivaban del análisis estático ${ }^{33}$. Es factible huir del estado de naturaleza, y para hacerlo no es preciso

- Pero si $V(A / B), V(B / B)$, entonces es que $A$ tiene capacidad de invasión individual sobre la población $B$, contra lo mantenido en la hipótesis inicial.

- Luego un p-racimo de $A$ nunca podrá invadir la población $B$ si un individuo $A$ no puede hacetlo. Q. E. D.

"2. Para entender la metodología de las explicaciones evolucionistas de mano invisible, me ha sido muy útil Vanberg, V., "Carl Menger's Evolutionaty and John R. Commons' Collective Action Approach to Institutions. A Comparison», Review of Political Economy, 1 (3) (1989), pp. 334-360, p. 340 .

* Esta afirmación también vale para el caso $\mathrm{N}$-personal. La conclusión principal del estudio del superjuego $\mathrm{N}$-personal del DP es que la cooperación puede emerger cualquiera que sea el número de jugadores (Taylor, The possibility of cooperation, p. 104). No obstante, y hablando informalmente - «que es todo lo que podemos hacer", reconoce Taylor-, resulta claro que la cooperación se vuelve más improbable según aumenta el tamaño del grupo de jugadores, pues hay más condiciones que han de ser satisfechas para que la cooperación constituya un equilibrio. La siguiente conclusión importante es que, para que la cooperación sea estable, al menos algunos jugadores han de ser cooperadores condicionales. De su número dentro del grupo, de la regla de cooperación condicional que empleen, del número crítico de cooperadores que precipite su propia cooperación $y$, desde luego, del factor de descuento que aplique cada jugador depende crucialmente el que la cooperación se mantenga o no a lo largo del ticmpo. 
i) Que los individuos se comuniquen entre sí ni lleguen a acuerdos explícitos. Los únicos «mensajes» relevantes son las respuestas que emiten.

ii) Que los que se interrelacionan experimenten simpatía o amistad entre ellos, o que sean parientes ${ }^{34}$. Incluso entre enemigos puede prosperar la cooperación ${ }^{35}$.

iii) Que los individuos obedezcan a una autoridad central. La cooperación puede verificarse sin constreñimientos externos; es suficiente el egoísmo racional de los implicados.

En cambio, las condiciones que han de darse necesariamente para la eclosión y estabilidad de la cooperación son:

a) Que la cooperación sea condicional. Y, más en concreto, que la regla de cooperación tenga las propiedades de la estrategia TIT-FOR-TAT, es decir, que sca amable, indulgente, vengativa, clara, robusta y colectivamente estable. Algunas de estas propiedades implican condiciones adicionales:

b) Que la reciprocidad cooperativa se practique en grupos lo bastante reducidos como para identificar sin ambigüedad a los no cooperantes, y poder tomar medidas contra ellos en encuentros ulteriores.

c) Que el factor de descuento sea lo bastante elevado como para que el futuro tenga importancia.

d) Que el contacto entre los miembros del pequeño grupo tenga lugar en un horizonte temporal indefinido, en el que ninguna de las partes posea certidumbre acerca de cuándo se interrumpirá la interacción.

e) Un aspecto de los análisis de Axelrod y Taylor, que ninguno de los dos hace suficientemente explícito, es que ambos dan por sentado - como, por otra parte, es norma entre los entendidos en teoría de juegos- que los participantes disfrutan de una racionalidad ilimitada o perfecta, lo que convierte en conocimiento común cosas tales como las opciones de conducta que cada uno posee, el número crítico de cooperantes que cada uno precisa para sumarse él a la cooperación, el valor acumulado y descontado de la corriente de pagos que una estrategia obtiene cuando tiene enfrente a otra, etc. La mayoría de estos presupuestos son decididamente irrealistas, aunque todavía se puede decir en su favor que constituyen aproximaciones válidas, en la medida en que la racionalidad limitada de los intervinientes se acerca a la racionalidad perfecta cuando el mismo juego es desarrollado numerosas veces, y las estrategias que arrojan peores resultados van extinguiéndose $y$, en cambio, se generalizan aquellas otras que proporcionan ventajas a sus usuarios. A su vez, estas estrategias

${ }^{34}$ Es curioso que la interesante circunstancia del parentesco, y las posibilidades de cooperación no condicional que tal circunstancia promueve, apenas son atendidas como se merecen por Axelrod. Una referencia ocasional al parentesco se encuentra en The evolution of cooperation, pp. 98-9.

${ }^{34}$ En el capítulo 4 de su libro, Axclrod muestra cómo la cooperación condicional emergió en la 1. ${ }^{a}$ Guerra Mundial entre los soldados de los bandos enfrentados. 
exitosas pueden afinarse aún más cuando son desplazadas por mutaciones conductuales posteriores que proporcionan beneficios todavía mayores ${ }^{36}$.

f) Una condición última afecta a los parámetros de pago, que han de tomar valores tales que $\mathrm{CC}>(\mathrm{DC}+\mathrm{CD}) / 2$. Si se incumple este requisito, el flujo de pagos para cada jugador se elevaría si, en vez de cooperar siempre, alternaran la cooperación y la defección en turnos sucesivos del superjuego, cuidándose además de que sus elecciones no fueran coincidentes en cada jugada. En circunstancias como ésta no se podría afirmar que se está jugando al Dilema del Prisionero.

\section{EL ANARQUISMO COMUNITARISTA}

El estudio de los microfundamentos de la cooperación espontánea nos ha permitido entender cómo pudo surgir ésta en un milieu enrarecido en que no se reconocen vínculos de parentesco entre los individuos, y en donde éstos son descritos como conductualmente unidimensionales (sólo capaces de disponer de una estrategia de conducta - aun si pueden lograr su conversión a otra- y no de todo un surtido de ellas). Nos abstendremos de negar el pan y la sal al modelo dinámico analizado por el poco realismo de sus presupuestos; hacer tal cosa sería manifiesta ingratitud, sobre todo si tenemos en cuenta lo mucho que hemos aprendido en el camino sobre las condiciones que han de concurrir para que se alcance una solución interna al problema de la cooperación colectiva en la provisión de bienes públicos (entre ellos, el orden social), enseñanzas que no dependen de la plausibilidad de los supuestos.

Ahora podemos afirmar que los requisitos que posibilitan la cooperación espontánea son tan exigentes que ninguna sociedad que merezca ese nombre los satisface; es decir: no existen anarquías perfectas. No obstante, aún diremos que una sociedad es anárquica si da una solución externa, pero descentralizada, a las dificultades de provisión de bienes públicos. Lo que se entiende por «solución al DP» (sea interna o externa) consiste en 1) hacer pasar a los jugadores del resultado subóptimo y cstable de la mutua defección al óptimo de la mutua cooperación, y 2) volver estable este último resultado que, prima facie, no lo es.

${ }^{36}$ Por desgracia no puedo adentrarme aquí en las interesantísimas cuestiones de racionalidad limitada y aprendizaje a través de la experiencia en juegos repetidos. Me limitaré a decir que el pionero en la defensa de los modelos de racionalidad limitada es Herbert Simon; véanse en especial los artículos recopilados en las secciones VII y VIII de su Models of bounded rationality, Cambridge (Mass.), The MIT Press, 1982. Para un tratamiento dentto de la teoría de juegos del tema de la racionalidad limitada, nada mejor que acudir a Binmore, $\mathbf{K}$., Essays on the Foundations of Game Theory, Cambridge (Mass.), Basil Blackwell, 1990, pp. 151-231, y Kreps, D., Gume Theony and Economic Modelling, Oxford, Clarendon Press, 1990, p.. 133-187. 


\subsection{Anarquía y comunidad}

Dentro de las anarquías imperfectas (que son las únicas con las que cabc contar), Taylor distingue las anarquías puras, que son aquellas sociedades en que

1. No hay concentración de los medios coercitivos. Es decir, existen instrumentos de control social (entre los que Taylor menciona la aprobación y desaprobación públicas, la amenaza de retirada de reciprocidad o las acusaciones de brujería) para asegurar el orden dentro del grupo, pero estos medios de coerción están distribuidos de forma estrictamente igualitaria.

2. No hay especialización política. Es decir, no se observa que haya individuos que jueguen papeles políticos (aunque sea a tiempo parcial), mientras que otros nunca to hacen. No se observa, por ejemplo, que haya miembros del grupo que estén autorizados a participar en asambleas decisorias, y otros no; que haya quienes formen parte de un consejo en que se diriman las disputas, y otros no, etc. La especialización política (unida fuertemente a condiciones de edad y sexo) tiende a desarrollarse a la par que el proceso de monopolización del poder.

En todas las sociedades se advierte algún grado de concentración de los recursos coercitivos y de especialización política, de modo que no existen tampoco, propiamente hablando, anarquías puras ${ }^{37}$, pero Taylor aún mantiene que han existido y existen sociedades sin Estado que son anarquías imperfectas e impuras, en que se da sólo un grado limitado de concentración de fucrza $\mathrm{y}$ de especialización política. Entre las socicdades sin Estado, hace esta clasificación:

1. Sociedades acéfalas.

2. Sociedades de redistribución centralizada.

2.1. Sistemas de «grandes hombres».

2.2. Jefaturas.

La concentración de medios coercitivos y la especialización política se incrementan a medida que nos movemos hacia abajo en esta clasificación.

En cuanto a la noción de comunidad, si bien reconoce Taylor que se trata de un concepto de «textura abierta» (Friedrich Waismann), menciona no obstante tres atributos que, en algún grado, tendrán todas las comunidades de las que él habla:

1) El conjunto de personas que componen la comunidad tienen valores y creencias comunes.

2) Las relaciones entre los miembros de la comunidad son directas y multilaterales. Que son directas quiere decir que no están mediadas por representantes, burócratas, instituciones, códigos, etc. Que son multilaterales significa

"Taylor, M., Community, Anarchy and Liberty, p. 6. 
que no se limitan a una función o rol, sino que abarcan muchos de ellos. La comunidad académica, por ejemplo, permite y a veces estimula relaciones intensas entre sus miembros, pero limitadas a una faceta muy específica, por lo que no se trataría de una comunidad en el sentido de Taylor.

3) Los integrantes de la comunidad practican entre ellos la reciprocidad, que Taylor describe como una combinación de altruismo de corto plazo y egoísmo de largo plazo ${ }^{38}$.

Distingue luego tres especies de comunidades: las primitivas, que estudian los antropólogos, a veces bajo la rúbrica de «sociedades sin Estado», y cuya clasificación hemos mencionado antes; las comunidades campesinas (algunas, al menos), que son internamente cuasi-anárquicas, pero que producen un fondo de renta (en especie, trabajo o dinero) para pagar a gente de fuera de la comunidad organizada como agencia de protección; y las comunidades intencionales, que, como las campesinas, se encuentran radicadas en sociedades con Estado y tienen un funcionamiento interno cuasi-anárquico: constituyen un intento deliberado de edificar un modo de vida global alternativo al de la sociedad de la cual se han retirado voluntariamente sus miembros.

El interés de Taylor se concentra en las comunidades primitivas, en la medida en que son las únicas cuya presencia no coexiste con la del Estado. Piensa que hay una afinidad clara entre anarquía y comunidad y que las características que hacen que un grupo sea anárquico (dispersión de los medios coercitivos, baja especialización política) hacen también que ese grupo constituya una comunidad, y viceversa. En especial, la comunidad resuelve el problema de la regresión, esto es, el problema de que la autoprovisión de bienes colectivos requiere que existan controles sociales pero, a su vez, los controles sociales son bienes colectivos cuyo mantenimiento plantea los mismos problemas de free-riding, que requeririan controles sociales de segundo nivel, etc. La comunidad consigue que los controles sociales (de primer nivel) sean efectivos a base de mantener bajos sus números; en un grupo suficientemente reducido es factible una solución interna al problema de suministro de controles sociales, lo que, a su vez, proporciona una solución externa al problema de provisión de orden social y otros bienes públicos. La fisión (fragmentación interna de un colectivo) es el proceso normal para conseguir que un grupo mantenga bajos sus efectivos, de modo que los procesos de fisión contribuyen indirectamente al mantenimiento del orden social.

38. 1 , pp, 28-9. La reciprocidad a que alude Taylor está entre la generalizada y la equilibrada de la tipología de Marshall Sahlins, incluyendo el primer polo pero no el segundo. Cf. Sahlins, M., Economía de la Edad de Piedra, Madrid, Akal, 1983, pp. 211-7, o mi propio artículo «De la sociedad cerrada a la sociedad abierta», Claves de razón práctica (en prensa). 


\subsection{Anarquia e igualdad}

Si la conclusión que se desprende del apartado precedente es que la anarquía requiere de la comunidad, la del presente será que la comunidad precisa una cierta igualdad económica, pues si se agranda la brecha entre ricos y pobres entonces la comunidad de valores desaparece, las relaciones interpersonales se hacen menos directas y multilaterales y la reciprocidad se debilita; en una palabra, quedan socavados los cimientos de la comunidad. Pensadores liberales, como Hayek o Nozick, creen que el mantenimiento de la igualdad económica requiere la persistente interferencia del Estado en las vidas de la gente y, por tanto, el sacrificio de la libertad (negativa) en el altar de la igualdad económica. En ausencia del Estado, incluso partiendo de una estricta igualdad de recursos, la simple incidencia del azar en sus diversas maneras hará que pronto las dotaciones diverjan. Si esto es así, y si la anarquía precisa de la comunidad y la comunidad de la igualdad económica, entonces -así concluye el argumento- la anarquía es inviable.

Taylor rechaza esta conclusión y defiende que un grado apreciable de igualdad económica puede ser mantenido sin el concurso del Estado, pero sólo en la comunidad. Empieza considerando el famoso ejemplo de Nozick sobre el jugador de baloncesto Wilt Chamberlain ${ }^{39}$. La historia es ésta: partimos de una distribución $\mathrm{D}_{1}$ que, por mor de la argumentación, tenemos por justa. Pero sucede que por entonces el célebre jugador de baloncesto Wilt Chamberlain firma un contrato con su equipo, de acuerdo con el cual cuando el equipo de Chamberlain juegue en casa 25 centavos del precio de cada entrada irán a los bolsillos del jugador. La temporada transcurre y al final de la misma hasta un millón de personas han pasado por la taquilla local, de modo que Chamberlain termina con 250.000 dólares, ingresos muy superiores al promedio que reciben los demás jugadores, $\mathrm{y}$ también a los salarios que perciben los espectadores. ¿En nombre de qué abstruso principio - se pregunta Nozickdeclararíamos injusta la nueva distribución $\mathrm{D}_{2}$, por mucho que consagre una flagrante desigualdad?

De modo en extremo interesante Taylor sugiere que la «justa desigualdad» de la que habla Nozick es el efecto perverso de un cierto free-riding. Un individuo puede desear pagar 25 centavos cada dos semanas por ver a Chamberlain, pero puede, a la vez, no desear el efecto agregado que se produciría si todos los demás hicieran lo mismo, a saber, el enriquecimiento fabuloso de Wilt Chamberlain. Ahora bien, si el grtpo es grande, el individuo considerará que lo que él haga en nada va a afectar al resultado agregado, con lo que optará finalmente por pagar la entrada y contribuir con ello a que Chamberlain amase su fortuna personal. Por otra parte, en las sociedades modernas, en que ya

\footnotetext{
"Anarchy, State, and Utopia, pp. 160-4.
} 
hay muchos ricos, a nadie importa demasiado que Chamberlain sea uno más de ellos. Pero en sociedades en que la riqueza y el poder están más igualitariamente repartidos, la gente puede valorar en alto grado esa igualdad y hacer o dejar de hacer cosas para mantenerla. Pueden dejar de hacer aquellas cosas que saben que contribuirán a crear grandes desigualdades de riqueza (y poder), y pueden hacer aquellas otras cosas que hagan posible la redistribución desde los temporalmente ricos a los temporalmente necesitados. Además, lo reducido del grupo favorece que pcrciban la incidencia de sus decisiones en el estado de cosas resultante.

Tales acciones y omisiones - aclara Taylor - no hay por qué considerarlas voluntarias ni han de serlo. La contribución individual a las prácticas niveladoras estará sostenida por sanciones positivas y negativas (normalmente tácitas) que tienden, como en otros contextos, a desalentar el free-riding. La igualdad es un resultado social deseable, que se alcanza - como otros bienes colectivos-conteniendo las actitudes oportunistas de quienes desean los resultados pero no desean contribuir a los mismos. Y no se trata, como piensan los socialdemócratas, de consentir el free-riding que precipita la desigualdad para luego hacer intervenir al Estado con medidas correctoras y redistributivas. Puede ser perfectamente la propia comunidad la que se encargue de velar por la producción de ese bien colectivo que es la igualdad económica, de la misma forma que se muestra autosuficiente para producir los demás bienes colectivos. Es verdad, admite Taylor ${ }^{40}$, que esto supondrá sacrificar algo de libertad para obtener algo más de igualdad, pero esto no es razón suficiente para rechazar los controles informales comunitarios, como tampoco lo es para rechazar el Estado benefactor.

\section{4. ¿POR OUÉ EXISTE EL ESTADO Y NO MÁS BIEN LA ANARQUIA?}

En la actualidad, la respuesta dominante a la pregunta que encabeza esta sección, y todo el artículo, es que fue la concurrencia fortuita de ciertos factores circunstanciales lo que precipitó la emergencia de Estados prístinos ${ }^{41}$ (Mesopotamia, Egipto, el Valle del Indo, China, Mesoamérica y Perú). Según las documentadas narraciones de Ellman Service o Michael Mann ${ }^{42}$, las poblaciones que atravesaton el umbral de las jefaturas para ingresar en la condición de

* Community, Anachy and Liberty, p. 102.

"La distinción Estados pristinos/secundarios se debe a Morton H. Fried, The Evolution of Political Society, Nueva York, Random House, 1967. La formación de Estados secundarios es fácil de entender; la amenaza de vecinos ya estatalizados hará que una sociedad emule la estructura de poder que tiene ante sí; en otro caso, csa socicdad corre cl riesgo de verse sometida y absorbida. Sea por una causa o por la otra, el Estado se difundirá culturalmente con rapidez.

${ }^{42}$ Service, E. R., Los origenes del Estado y de la civilización, Madrid, Alianza Editorial, 1984, pp. 185-286, y Mann, M., The sources of social power, Cambridge, Cambridge U. P., 1986, pp. 73-127. 
Estados (en un entorno en el que no había ya otros Estados), lo hicieron bajo la presión de una o ambas de estas circunstancias:

i) Circunscripción ambiental: el territorio ocupado por el grupo está circundado por barreras naturales (montañas, desiertos, mares) y/o por suelos de valor ecológico muy inferior.

ii) Circunscripción social: el grupo se halla acotado en su expansión por la presencia de grupos rivales asentados en los terrenos adyacentes.

Service considera --y Taylor le sigue en esto- que la circunscripción ambicntal ${ }^{43}$, por sí sola, únicamente da cuenta a satisfacción de los casos de Egipto y Perú ${ }^{44}$. Seguramente debieron confluir ambos tipos de circunscripción para detener el normal proceso de fisión que se observa en las comunidades primitivas. Al quedar circunscrita (enjaulada, dice Mann con mayor contundencia expresiva) una comunidad, pronto sus efectivos humanos rebasan el umbral crítico por encima del cual entra en colapso la solución interna al mantenimiento de los controles sociales, y queda suscitado en toda su crudeza el que he denominado "problema de la regresión»: que los controles sociales garantes del orden son un bien colectivo que precisa, para su sostenimiento, de nuevos controles sociales, y así ad infinitum ${ }^{45}$. Se dan entonces las condiciones para que el Estado, como innovación cultural, proporcione una respuesta al recién planteado problema de la regresión. Argumentando contra la teoría marxista ${ }^{46}$ del nacimiento del Estado, Taylor afirma:

La posición a la que hemos llegado es, entonces, que la formación del Estado hinca sus raíces, no en el crecimiento de la desigualdad económica, sino en la combinación de condiciones que fortalecen un liderazgo que se encuentra ya en sociedades sin Estado, y condiciones que hacen la fisión imposible o indeseable ${ }^{47}$.

${ }^{4}$ Que es en la que Robert Carneiro basa casi con exclusividad su teoría de la formación de Estados prístinos. Véase su "A Theory of the Origin of the State", Science, 169 (1970), pp. 733-8.

* Service, E. R., Los orgenes del Estado y la civitización. pp. 321-2.

${ }^{4}$ Una formulación de este problema se puede hallar en Elster, I., Solomonic judgements, Cambridge, Cambridge U.P., 1989, pp. 34-5. Un tratamiento desde la teoría de juegos de las metanormas (las normas que establecen que se debe castigar a los que no castigan una defección) se encuentra en Axelrod, «An Evolutionary Approach to Norms», American Political Sclence Review, 80 (4) (1986), pp. 1095-1111.

t La teoría marxista se deja resumir en estos tèrminos: el avance tecnológico (en la agricultura ante todo) hace posible por primera vez la formación de un excedente que puede ser intercambiado. Tal cosa estimula el comercio y la produción de mercancías para el intercambio, lo que, a su vez, hace emerger una gama de especialistas (empresarios, comerciantes, etc.) liberados por la existencia del excedente de la participación en la producción. Como resultado de esta división del trabajo y de la actividad contercial, se desarrolla la desigualdad económica, lo que conduce a la estratificación en clases sociales, basada en el acceso diferencial a importantes medios de producción. Finalmente, se forma el Estado por la clase dominante y con objeto de mantener su privilegiado acceso a los recursos productivos.

${ }^{47}$ Community, Anarchy and Liberty, p. 138. 
Con ello la solución externa centralizada, encarnada en el Estado, se va extendiendo a todos o la mayoría de los problemas de suministro de bienes colectivos, pues el Estado se autoalimenta de las condiciones que él mismo crea: propicia el crecimiento de las poblaciones, destruye los requisitos que posibilitan la comunidad y contribuye activamente a que los individuos desaprendan a cooperar unos con otros; es decir, continuamente recrea y amplía las bases de su propia indispensabilidad. En las sociedades democráticas, en que el sector público ha alcanzado dimensiones colosales, los ciudadanos acaban por pensar que sus responsabilidades colectivas concluyen cuando abonan sus impuestos y trasladan, así, al Estado el cometido de suministrar los bienes colectivos. Al pagar sus impuestos, el ciudadano paga para dejar de serlo, o sea, para apartar de su atención los asuntos públicos. «Podríamos decir que el Estado es como una droga adictiva: cuanto más tenemos de él, más lo necesitamos, y más dependemos de su presencia» ${ }^{48}$.

\section{VALORACION FINAL}

Espero que se me concederá que Michael Taylor es uno de los anarquistas más persuasivos y razonables con que le es dable a uno encontrarse. Incluso para los que no profesamos esa fe política resulta en extremo difícil localizar un punto de desacuerdo con lo que dice. A diferencia de lo que es habitual con otros anarquistas, Taylor no se instala de entrada en un optimismo antropológico rousseauniano («el hombre es naturalmente bueno; son las instituciones las que lo corrompen»); a falta de ese optimismo, no se retrepa tampoco en una presunta maleabilidad de la condición humana por medio de la educación, capaz de enderezar la madera torcida de la que los hombres estamos hechos. Parece saber sobradamente que ambos supuestos «perdonan» el problema del orden social (despojándolo, de paso, de todo interés intelectual), en lugar de abordar su resolución. Haciendo uso de una sabiduría metodológica encomiable, Taylor «se pone en lo peor»; acepta, al menos de entrada, la imagen sumarísima y moralmente poco atrayente del ser humano que podría proporcionarnos un economista ortodoxo o neoclásico (el conocido homo economicus), y explica que incluso con sujetos de tan liviano espesor moral es dable un orden social no apuntalado por ninguna autoridad central. Es esta combinación de premisas hobbesianas y conclusiones anarquistas lo que conficre su peculiar fuerza seductora a la postura de Taylor ${ }^{49}$. No sólo la ejemplar frugalidad de sus supuestos morales parece alejarle de los partidarios de una sociedad sin Estado; también el derroche de orfebrería analítica que Taylor prodiga suele ser extraño a los anarquistas, cuya capacidad teórica y conceptual

${ }^{48}$ Taylor, M., The possibility of cooperation, p. 168.

4 Cf. McLean, L. «The Social Contract in Leviathan and the Prisoner's Dilemma Supergame», Political Studies, 29 (3) (1981), pp, 339-351, p. 346. 
tiende casi siempre a quedar devorada por el arrasador aliento épico y regenerador que los embarga. Muy módicas son las dosis de este aliento épico y regenerador que se podrán encontrar en los escritos de Taylor, y muy pocas son también las ilusiones que se hace este autor sobre la viabilidad futura, en un mundo superpoblado, de las comunidades anarquistas existentes, y aún menos de la capacidad de contagio y propagación de esta forma de orden social.

Por otro lado, hay que recordar la circunstancia de que «la mayor parte de la historia humana no ha contado con la presencia de Estados» ${ }^{50}$. La anarquía fue la solución efectiva al problema del mantenimiento y perpetuación del orden social durante la casi totalidad del pasado de nuestra especie. Taylor proporciona una explicación en extremo coherente e inteligible de por qué fue esto así, y también da cuenta del tipo de cosas que hubieron de ocurrir para que esta solución tan señaladamente estable entrara en crisis, y las razones que hay para suponer que esta crisis es punto menos que irreversible: estamos condenados al Estado e incluso a desear más Estado cuanto más tenemos de él. No obstante todo lo cual, mantiene Taylor la deseabilidad de la anarquía, y quien lo lee no puede sustraerse a la impresión de que está hablando de una deseabilidad moral, y no de otra cosa. En otras palabras: está más que sugiriendo que los valores cálidos de la igualdad, la solidaridad, la comunidad de ideas, la participación política directa, etc, son moralmente superiores a los más frios de la libertad, el respeto, el individualismo, la diversidad de pareceres y la representación en la esfera pública ${ }^{51}$. Esta predilección «de izquierdas» por los valores de la moral cálida (microgrupal) merecería muchos comentarios, pero uno en especial me parece más apremiante que cl resto. Nos hemos habituado, como micmbros de la civilización, a considerar impostergables ciertos derechos individuales básicos - derechos demarcadores de espacios privadosque sencillamente no juegan ningún papel en una moral anarco-comunitaria, y que incluso parecen contrarios a su espiritu. Sólo quien crea ingenuamente en la bondad natural del hombre encontrará alguna ventaja en la ausencia de esta delimitación entre esferas privadas protegidas, ausencia que es consustancial a la vida en régimen de comunidad.

Se podría aquí aducir que es tramposo hacer valer preferencias que se han formado al calor de siglos de contacto con la civilización para cohonestar los principios de la moral fría, característicos de esa misma civilización, y para intentar persuadir de su presunta superioridad sobre la moral cálida. Probablemente, si hubiéramos seguido desenvolviéndonos èn un entorno comunitarista, nos parecería incontestable que los méritos de la moral cálida sobrepujan

\footnotetext{
" Hall, J. A., e Ikenberry, G. J., El Evłado, Madrid, Alianza Editorial, 1993, p. 35.

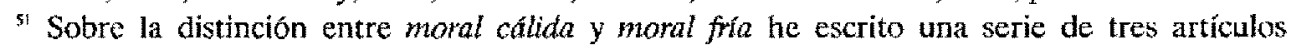
— «De la sociedad cerrada a la sociedad abierta», «Mercado frente a solidaridad» y «Moral fría y moral cálida» - que, si todo va bien, estarấn en curso de publicación en la revista Claves de razón príctica cuando vean la luz estas páginas.
} 
los de cualquier otra moral imaginable. El argumento de que es normal (y, por normal, intelectualmente poco valioso o demostrativo) preferir el statu quo cuando es el statu quo el que ha modelado las preferencias de uno ${ }^{52}$, se puede emplear evidentemente, y entre otras cosas, para reducir a cenizas las pretendidas legitimaciones (parciales) del orden institucional a las que son propensos algunos neocontractualistas, o para poner de manifiesto su vacuidad. Pero a todo esto se puede redargüir que la senda que han tomado nuestras predilecciones morales bajo la atmósfera de la civilización es seguramente tan irreversible como la senda institucional de la misma civilización y que, tanto en un caso como en otro, «nos encontramos aquí y no en ninguna otra parte». De poco vale apelar a unos supuestos gustos morales intactos por la presión social y «realmente auténticos» o no alienados: ya sabemos que tal cosa no existe. Y tampoco se llega mucho más lejos ensayando un rearme voluntarista que nos haga creer que cualquier cosa que haya sido producto de la fábrica humana (entre ellas la civilización o los gustos morales anejos a la misma) se puede deshacer de la misma forma que se hizo. La inercia de los resultados y circunstancias colcctivos es formidable, $\mathrm{e}$ incluso en aquellos casos en que es palpable la suboptimalidad de una situación social no es en absoluto evidente que pueda ser removida o extirpada mediante un proceso de cirugía institucional conscientemente dírigido (como tampoco es evidente que este proceso quirúrgico no vaya a agravar la situación que pretendía mejorar); más aún cabe pensarlo en aquellas cuestiones (como la sedicente superioridad moral, para algunos, de la comunidad sobre la civilización) en que dista mucho de haber unanimidad de pareceres, y en que consiguientemente la voluntad de cambio social deliberado es menos intensa, o está menos extendida o ambas cosas.

Mis reservas mayores, como se ve, no van dirigidas contra la indagación teórica de Taylor -que me parece ejemplar en más de un sentido--, sino más bien contra los presupuestos valorativos subyacentes a sus propuestas de modificación del orden institucional; propuestas que, por lo demás, están manifestadas con gran contención y sin llegar nunca a ofuscar su perspicacia analítica.

${ }^{52}$ Este argumento se encuentra, por ejemplo, en Anthony de Jasay, El Estado. La lógica del poder político, Alianza Fditorial, 1993, p. 140. 